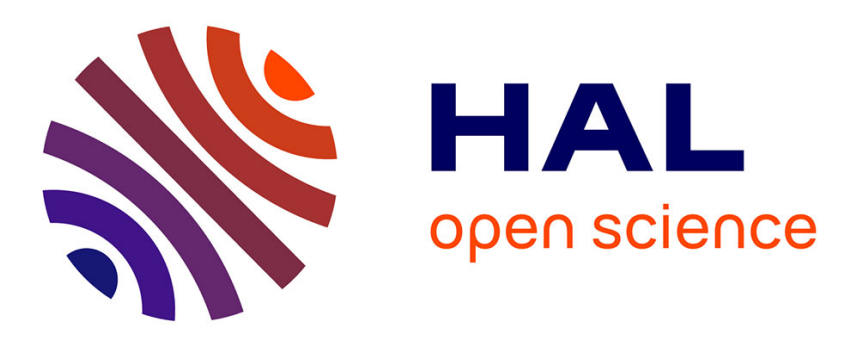

\title{
Correlating sulfur solubility with short-to-intermediate-range ordering in the structure of borosilicate glasses
}

\author{
Rajan Saini, Saurabh Kapoor, Daniel R Neuville, Randall E Youngman, \\ Bianca Cerrutti, John S Mccloy, Hellmut Eckert, Ashutosh Goel
}

\section{To cite this version:}

Rajan Saini, Saurabh Kapoor, Daniel R Neuville, Randall E Youngman, Bianca Cerrutti, et al.. Correlating sulfur solubility with short-to-intermediate-range ordering in the structure of borosilicate glasses. The Journal of physical chemistry, In press, 10.1021/acs.jpcc.1c08654 • hal-03500011

\section{HAL Id: hal-03500011 \\ https://hal.science/hal-03500011}

Submitted on 21 Dec 2021

HAL is a multi-disciplinary open access archive for the deposit and dissemination of scientific research documents, whether they are published or not. The documents may come from teaching and research institutions in France or abroad, or from public or private research centers.
L'archive ouverte pluridisciplinaire $\mathbf{H A L}$, est destinée au dépôt et à la diffusion de documents scientifiques de niveau recherche, publiés ou non, émanant des établissements d'enseignement et de recherche français ou étrangers, des laboratoires publics ou privés. 


\title{
Correlating sulfur solubility with short-to-intermediate-range ordering in the structure of borosilicate glasses
}

\author{
Rajan Saini, ${ }^{1}$ Saurabh Kapoor, ${ }^{2}$ Daniel R. Neuville, ${ }^{3}$ Randall E. Youngman. ${ }^{4}$ \\ Bianca Cerrutti, ${ }^{5}$ John S. McCloy ${ }^{6}$ Hellmut Eckert ${ }^{5,7}$, Ashutosh Goel ${ }^{1, *}$ \\ ${ }^{1}$ Department of Materials Science and Engineering, Rutgers, The State University of New \\ Jersey, Piscataway, NJ 08854-8065, United States \\ ${ }^{2}$ Centre of Excellence, Sterlite Technologies Ltd, MIDC Waluj, Aurangabad, 431136, India \\ ${ }^{3}$ Institut de Physique du Globe de Paris, CNRS-Géomatériaux, Université de Paris, 1 rue Jussieu, \\ 75005 Paris, France \\ ${ }^{4}$ Science and Technology Division, Corning Incorporated, Corning, NY 14831, United States \\ ${ }^{5}$ Institute of Physical Chemistry, WWU Münster, Corrensstraße 30, D48149 Münster, Germany \\ ${ }^{6}$ School of Mechanical and Materials Engineering, Washington State University, PO Box 64290, \\ Pullman, WA 99164-2920, United States \\ ${ }^{7}$ São Carlos Institute of Physics, São Paulo University, 13566-590, São Carlos, SP, Brazil
}

* Corresponding author

Email: ag1179@ soe.rutgers.edu; Phone: +1-848-445-4512 


\begin{abstract}
The present study focuses on understanding the structural dependence of sulfur (as $\mathrm{SO}_{4}{ }^{2-}$ ) solubility in $\mathrm{Na}_{2} \mathrm{O}-\mathrm{B}_{2} \mathrm{O}_{3}-\mathrm{SiO}_{2}$ glasses over a broad composition space exhibiting a rich variety of structural associations. The focus is on probing the impact of the (1) structural role of $\mathrm{Na}^{+},(2)$ degree of polymerization, and (3) network former connectivity (formation of $\mathrm{Si}-\mathrm{O}-\mathrm{B}$ and $\mathrm{B}-\mathrm{O}-\mathrm{B}$ linkages) on sulfur solubility in borosilicate glasses. By employing a suite of state-of-the-art characterization techniques, including ICP-OES, MAS NMR spectroscopy, and Raman spectroscopy, an inverse correlation has been established between the sulfur solubility and the degree of network polymerization in the glasses across the investigated composition space. While the formation of $\mathrm{SO}_{4}{ }^{2-}$ can successfully compete with the network depolymerization mechanisms (i.e., creation of nonbridging oxygens) and induce re-polymerization in the glass network, the $\mathrm{BO}_{3} \rightarrow \mathrm{BO}_{4}$ conversion takes precedence. The results from this study, when extended to more complex borosilicate-based glass chemistries, will not only add to our understanding of the fundamental science controlling the sulfur solubility in borosilicate-based real-world nuclear waste glasses, but will also form a basis for the development of non-empirical Quantitative Structure - Property Relationships based predictive models.
\end{abstract}

Keywords: Borosilicate glass; nuclear waste; MAS NMR spectroscopy; Raman spectroscopy; ICPOES. 


\section{Introduction}

Owing to its low solubility (on the order of $1 \mathrm{wt} . \% \mathrm{SO}_{3}$ ) in borosilicate based radioactive waste glasses, sulfur (as sulfate, $\mathrm{SO}_{4}{ }^{2-}$ ) has been one of the two critical factors (the second one being the long-term chemical durability) impeding the loading of Hanford low-activity waste (LAW) into vitreous waste forms. ${ }^{1}$ Exceeding the solubility limit of sulfate in borosilicate-based nuclear waste glass melt results in the formation of an immiscible sulfate salt layer (known as "gall" or yellow phase) that floats on the top of the melt. ${ }^{2,3}$ The low-viscosity, electrically conductive salt layer, being rich in water-soluble alkali/alkaline-earth sulfates along with specific radionuclides (such as ${ }^{99} \mathrm{Tc},{ }^{90} \mathrm{Sr}$, and ${ }^{137} \mathrm{Cs}$ ), can cause several problems for the melter-for example, corrosion of container walls, shorting of the heating electrodes, risks of explosion due to low viscosity and low density — thus, severely impacting its performance and lifetime. ${ }^{4-6}$

In order to avoid the above-mentioned complications, and for the safe operation of the melter, empirical models have been developed to predict the practical limit of salt solubility in the melt as a function of feed composition. For example, Vienna et al., ${ }^{6}$ based on 253 simulated Hanford LAW glass compositions, established an empirical model to predict the $\mathrm{SO}_{3}$ solubility in LAW glasses as a function of the concentration of different components in the melter feed (as shown in Eqn. 1).

$$
W_{S O_{3}}^{\text {Pred }}=\sum_{i=1}^{q} s_{i} n_{i}+\operatorname{selected}\left(\sum_{i=1}^{q} s_{i i} n_{i}^{2}+\sum_{j=1}^{q-1} \sum_{k=j+1}^{q} s_{j k} n_{j} n_{k}\right)
$$

where, $W_{\mathrm{SO}_{3}}^{\text {Pred }}$ is the predicted $\mathrm{SO}_{3}$ solubility in weight percent, $q$ represents the number of components in the composition with $s$ being the coefficient and $n$ is the normalized mass fraction of the component. Further, Muller et al. ${ }^{7}$ extended this $\mathrm{SO}_{3}$ solubility model to a 31-term partial 
quadratic mixture model (shown in Equation 2) using the data of $485 \mathrm{LAW}$ glasses with $\mathrm{SO}_{3}$ solubility (wt.\%) ranging from 0.15 to 0.83 .

$$
S O_{3}(w t \%)=\sum_{i=1}^{18} a_{i} x_{i}+\text { selected }\left\{\sum_{i<}^{q-1} \sum_{j}^{q} a_{i j} x_{i} x_{j}\right\}
$$

where $q$ represents the number of components in the composition with $a$ being the coefficient, and $x$ is the normalized mass fraction of the component. ${ }^{8}$

The above-discussed models, though conservative (in terms of $\mathrm{SO}_{3}$ loading), may work well for the current processing flowsheet where LAW is supposed to be pre-treated before vitrification. However, owing to their empirical nature, it will be impossible for these models to predict LAW glass compositions with higher $\mathrm{SO}_{3}$ solubility (> $1 \mathrm{wt} . \%$ ), as anticipated in the case of a direct feed approach. ${ }^{4}$

Further, the implementation of a direct feed approach not only poses a challenge for the established models for predicting the $\mathrm{SO}_{3}$ solubility in LAW glasses, but it is also expected to aggravate the complexity of high level waste (HLW) vitrification by considerably increasing the sulfate content in the waste stream (since the pre-treatment of HLW for sulfate removal before vitrification shall be by-passed). ${ }^{9}$ Therefore, sulfur tolerant HLW glasses need to be designed to avoid salt segregation in the Joule Heated Ceramic Melter (JHCM). Nevertheless, the existing $\mathrm{SO}_{3}$ solubility models do not perform well with HLW glass compositions, as these models are based on a statistical rather than Quantitative Structure - Property Relationships (QSPR) based approach and are confined to the compositional database of LAW glasses whose range of the constituent oxides is significantly different from that in HLW glasses. ${ }^{10}$

The above-mentioned challenges posed by the increasing sulfate content in direct-feed LAW and HLW glasses can be addressed by one of the following two approaches: (1) follow a trialand-error approach to collect enormous amounts of data on LAW and HLW glasses with 
enhanced $\mathrm{SO}_{3}$ loadings leading to the development of empirical composition- $\mathrm{SO}_{3}$ solubility based predictive models, or (2) combine the strengths of experimental and computational materials science to understand (and elucidate) the underlying compositional and structural descriptors controlling $\mathrm{SO}_{4}{ }^{2-}$ solubility in borosilicate glasses. Ultimately this should lead to the development of a unified composition-structure- $\mathrm{SO}_{4}{ }^{2-}$ solubility-based model that can help in the rational design of both LAW and HLW glasses with enhanced $\mathrm{SO}_{3}$ loadings, irrespective of the differences in their compositional ranges. While the design of advanced glass formulations using the first approach is difficult, if not impossible, the implementation of the second approach requires a new level of conceptual understanding about the impact of structural organization of borosilicate-based glasses on their sulfur solubility.

The challenge with the implementation of the second approach is the limited amount of literature dealing with the composition-structure- $\mathrm{SO}_{4}{ }^{2-}$ solubility relationships in borosilicate glasses. The investigated glass systems are compositionally complex (comprising multiple framework and non-framework moieties). In addition, to date only empirical correlations between composition and properties have been published. ${ }^{2,3,11-20}$ Systematic model studies are

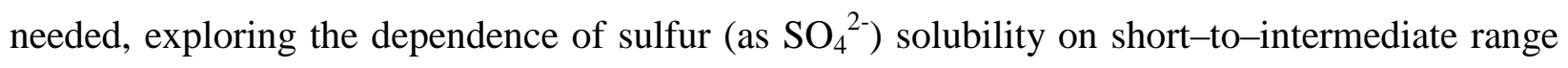
ordering in glasses with simplified compositions, before introducing compositional complexity.

In the present contribution we investigate the dependence of $\mathrm{SO}_{3}$ solubility in $\mathrm{Na}_{2} \mathrm{O}-\mathrm{B}_{2} \mathrm{O}_{3}-$ $\mathrm{SiO}_{2}$ based glasses on composition over a broad composition space, traversing all the four regions (in terms of relative ratios $R=\mathrm{Na}_{2} \mathrm{O} / \mathrm{B}_{2} \mathrm{O}_{3}$, and $K=\mathrm{SiO}_{2} / \mathrm{B}_{2} \mathrm{O}_{3}$ ) in the sodium borosilicate ternary, as described by the Dell-Yun-Bray (DYB) structural description (see Figure 1), ${ }^{22-24}$ exhibiting a rich variety of structural associations. The DYB model divides the compositional space in the $\mathrm{Na}_{2} \mathrm{O}-\mathrm{B}_{2} \mathrm{O}_{3}-\mathrm{SiO}_{2}$ ternary system into four regions based on the $R$ (= 
$\left.\mathrm{Na}_{2} \mathrm{O} / \mathrm{B}_{2} \mathrm{O}_{3}\right)$ and $K\left(=\mathrm{SiO}_{2} / \mathrm{B}_{2} \mathrm{O}_{3} \leq 8\right)$ values, as has been shown in Figure $1 .{ }^{23,}{ }^{24}$ Region 1 comprises the glasses with $R<0.5$. Region 2 belongs to the glasses with $0.5 \leq R \leq R^{*}$, where $R^{*}$ $(=0.5+K / 16)$ is the value

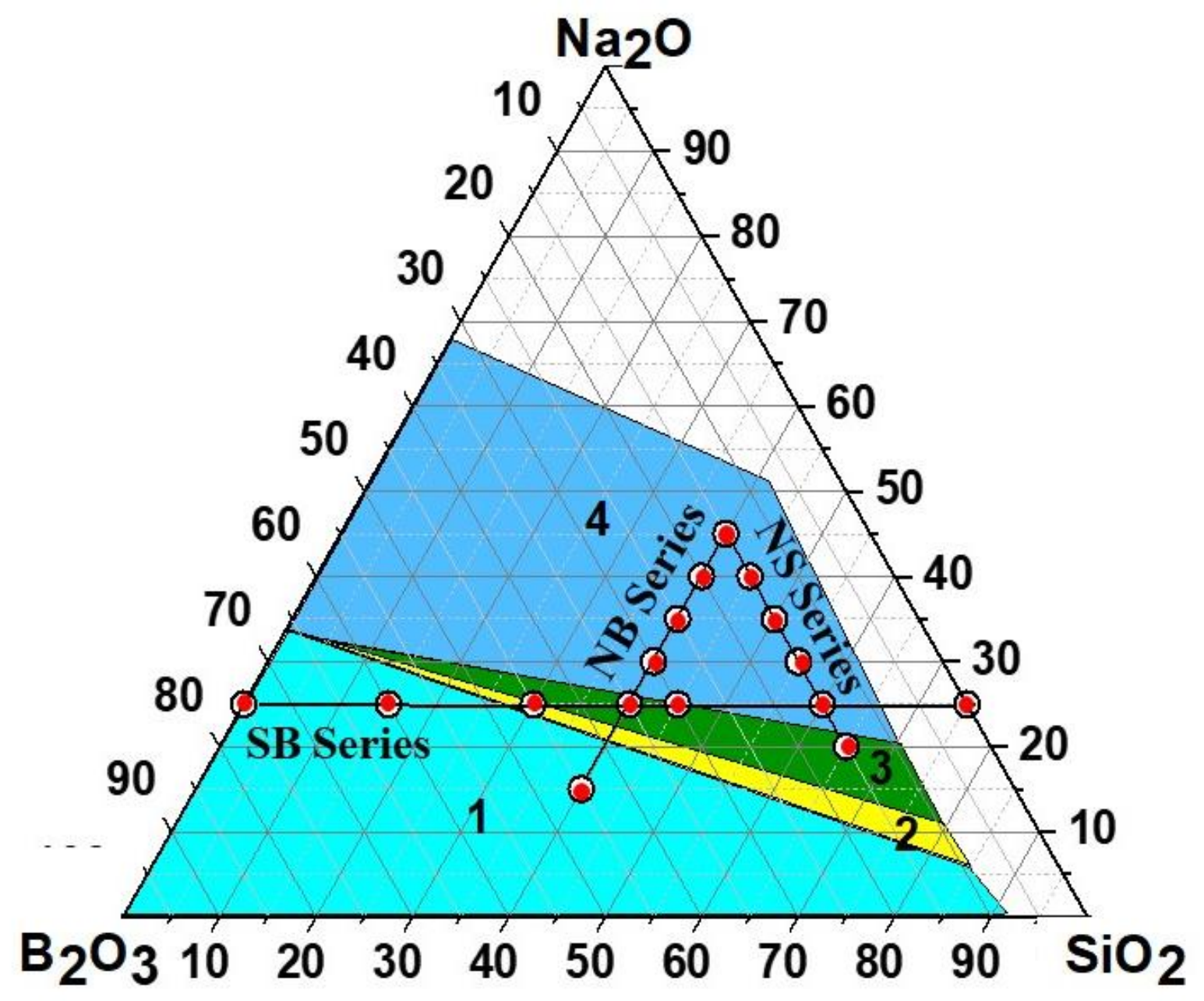

Figure 1. Compositions of the baseline $\mathrm{Na}_{2} \mathrm{O}-\mathrm{B}_{2} \mathrm{O}_{3}-\mathrm{SiO}_{2}$ glasses investigated in the present study overlaid upon the Dell-Yun-Bray (DYB) ternary diagram. The numbers 1 to 4 represent the four regions as described in the DYB model for sodium borosilicate ternary system. The white circles represent the batched compositions while the red circles represent the experimentally measured glass compositions.

at which anionic functionalization of boron still proceeds exclusively by the conversion of threeto four coordinated boron. The value of $R^{*}$ assumes that the four-coordinated boron species are 
stabilized by four B-O-Si linkages units, which is the structural situation in the mineral reedmergnerite $\left(\mathrm{NaBSi}_{4} \mathrm{O}_{10}\right)$. In Region 3, defined by $R^{*} \leq R \leq(0.5+K / 4)$, the additional $\mathrm{Na}^{+}$(left after the formation of $\mathrm{B}^{4}$, i.e., $\mathrm{B} \emptyset_{4}$, units) create NBOs in the silicate network and subsequently, in the borate units, defined by Region 4, where $(0.5+K / 4) \leq \mathrm{R} \leq(2+K)$. Accordingly, a total of three sets of glass compositions have been designed with: (1) variation of $R$ at fixed $\mathrm{SiO}_{2}$ content (NB series), (2) variation of $K$ at fixed $\mathrm{Na}_{2} \mathrm{O}$ content ( $\mathrm{SB}$ series), and (3) variation of the $\mathrm{Na}_{2} \mathrm{O} / \mathrm{SiO}_{2}$ ratio at fixed $\mathrm{B}_{2} \mathrm{O}_{3}$ content (NS series). Previous structural work on borosilicate glasses suggests that such compositional variations influence the boron speciation (fractions of three- versus four-coordinated species, $\mathrm{B}(\mathrm{III})$ and $\mathrm{B}(\mathrm{IV})$ ), the concentration of non-bridging oxygens (NBOs) bonded to $\mathrm{B}(\mathrm{III})$ or silicon, the concentrations of ring-to-non-ring units and the distributions of $\mathrm{Si}-\mathrm{O}-\mathrm{Si}, \mathrm{Si}-\mathrm{O}-\mathrm{B}$, and $\mathrm{B}-\mathrm{O}-\mathrm{B}$ connectivity. ${ }^{22,}{ }^{24-29}$ In addition, the extent of network former mixing may be limited by chemical segregation and/or phase separation phenomena. All these variations in the short-to-medium range structure are expected to have an impact on the sulfur solubility in borosilicate glasses. ${ }^{11,30}$ In turn, incorporation of sulfur may affect network former speciation and network former - network modifier interactions. Thus, the present study aims to employ a suite of state-of-the-art spectroscopic techniques to decipher the underlying structural drivers governing the sulfur solubility in sodium borosilicate glasses.

\section{Experimental details}

\subsection{Synthesis of baseline borosilicate glasses}

All glasses were synthesized by the melt quench technique. High purity powders of $\mathrm{SiO}_{2}$ (Alfa Aesar; >99.5\%), $\mathrm{H}_{3} \mathrm{BO}_{3}$ (Alfa Aesar; >98\%), and $\mathrm{Na}_{2} \mathrm{CO}_{3}$ (Fisher Scientific; >99.5\%) were used as precursors. The homogenous batches corresponding to $70 \mathrm{~g}$ of oxides were melted in 
$90 \% \mathrm{Pt}-10 \% \mathrm{Rh}$ crucibles (loosely covered with a $\mathrm{Pt}$ lid) in an electric furnace in the temperature range of $950-1650{ }^{\circ} \mathrm{C}$ for $1 \mathrm{~h}$. The melts were quenched on a copper plate maintained at room temperature.

\subsection{Synthesis of sulfur-containing borosilicate glasses}

$\mathrm{Na}_{2} \mathrm{SO}_{4}$ has been used as a precursor for adding sulfur $\left(\mathrm{as} \mathrm{SO}_{3}\right)$ to the baseline glasses. The batch calculations were made to ensure that the total content of $\mathrm{Na}_{2} \mathrm{O}$ in the glass remains constant. The example below describes the methodology used to synthesize sulfur-containing glasses in the present study. When adding $x$ mol. $\% \mathrm{SO}_{3}$ to a baseline composition, for example, $40 \mathrm{Na}_{2} \mathrm{O}-20 \quad \mathrm{~B}_{2} \mathrm{O}_{3}-40 \quad \mathrm{SiO}_{2}$, the batch was calculated as $(40-x) \quad \mathrm{Na}_{2} \mathrm{O}-20 \mathrm{~B}_{2} \mathrm{O}_{3}-40 \quad \mathrm{SiO}_{2}-x$ $\mathrm{Na}_{2} \mathrm{SO}_{4}$ (mol.\%), where $x$ mol. $\% \mathrm{Na}_{2} \mathrm{SO}_{4}$ serves as the source of $x$ mol. $\% \mathrm{Na}_{2} \mathrm{O}$ and $x$ mol.\% $\mathrm{SO}_{3}$. Accordingly, a batch corresponding to composition (40-x) $\mathrm{Na}_{2} \mathrm{O}-20 \mathrm{~B}_{2} \mathrm{O}_{3}-40 \mathrm{SiO}_{2}$ was prepared and melted in a Pt-Rh crucible using the methodology described in section 2.1. Once the melt (poured on the copper plate) cooled to room temperature, the resulting glass was kept back in the same Pt-Rh crucible and $x$ mol. $\% \mathrm{Na}_{2} \mathrm{SO}_{4}$ was added to it. The Pt-Rh crucible was loaded in the furnace and covered with a Pt lid. The mixture was melted at the same temperature (as the base glass) for another 1 hour followed by quenching of the melt by pouring it on a copper plate.

\subsection{Compositional analysis of glass samples}

The amorphous/crystalline nature of the resulting samples has been confirmed by powder (particle size $<45 \mu \mathrm{m}$ ) X-ray diffraction (PANalytical X'Pert Pro X-ray diffractometer with $\mathrm{Cu}$ $\mathrm{K}_{\alpha}$ radiation; $45 \mathrm{kV} ; 40 \mathrm{~mA} ; 2 \theta$ range of $10-90^{\circ}$; step-size of $0.013^{\circ}$; dwell time of $0.01 \mathrm{~s}$ at each step). 
The compositional analysis of the glass samples has been performed by inductively coupled plasma - optical emission spectroscopy (ICP-OES; Perkin Elmer Optima 8300). Prior to analysis for $\mathrm{B}_{2} \mathrm{O}_{3}$, the glass samples were digested in a 1:1 (by volume) hydrofluoric acid (37 w/w) to water solution (by volume). Prior to $\mathrm{SiO}_{2}$ analysis, a mixture of $50 \mathrm{mg}$ glass powder (particle size $<45 \mu \mathrm{m}$ ), $250 \mathrm{mg} \mathrm{Na} \mathrm{B}_{4} \mathrm{O}_{7}$ and $250 \mathrm{mg} \mathrm{Na} \mathrm{CO}_{3}$ was prepared and fused at $950{ }^{\circ} \mathrm{C}$. The resulting fused product was subsequently digested by stirring in a 1:1 (by volume) hydrochloric acid to water solution. In the case of sodium analysis, samples were digested in $\mathrm{HCl} / \mathrm{HF}$ mixtures using multiple heating and drying cycles. The resulting samples were ultimately dissolved in 1:1 (by volume) hydrochloric acid to water solution. For sulfur analysis, a mixture of $250 \mathrm{mg}$ glass powder, $500 \mathrm{mg} \mathrm{Na} \mathrm{B}_{4} \mathrm{O}_{7}$ and $500 \mathrm{mg} \mathrm{Na} \mathrm{CO}_{3}$ was fused at $950{ }^{\circ} \mathrm{C}$ followed by digestion (by stirring) in a 1:1 (by volume) hydrochloric acid to water solution. Each of the above-described solutions has been analyzed via ICP-OES against a matrix-matched blank and standard.

Figure 1 and Table S1 present the batched and analyzed compositions (using ICP-OES) of the sulfur-free (baseline) glasses investigated in the present study. The glasses have been labeled as NB- $x$, SB- $y$ and NS- $z$, where $x$ and $z$ represent the molar concentrations of $\mathrm{Na}_{2} \mathrm{O}$, while $y$ represent the molar concentrations of $\mathrm{B}_{2} \mathrm{O}_{3}$ in the respective series.

\subsection{Structural analysis of glasses}

The structural analysis of the glass samples has been performed by ${ }^{11} \mathrm{~B},{ }^{23} \mathrm{Na}$ and ${ }^{29} \mathrm{Si}$ magic angle spinning - nuclear magnetic resonance (MAS NMR) and Raman spectroscopy. ${ }^{11}$ B MAS NMR spectra have been recorded on a Bruker Avance Neo $600 \mathrm{MHz}$ spectrometer (14.1 T) using a commercially available $2.5 \mathrm{~mm}$ MAS NMR probe. Single resonance ${ }^{11}$ B MAS NMR spectra have been collected using powdered samples packed into zirconia rotors and spun at 15.0-20.0 
kHz. All the data has been acquired at $14.1 \mathrm{~T}$ (192.63 MHz resonance frequency) using RF pulses of $0.8 \mu$ s (corresponding to a $\pi / 6$ tip angle), $1 \mathrm{~s}$ recycle delays, and signal averaging over at least 1000 acquisitions. ${ }^{11} \mathrm{~B}$ chemical shifts are reported relative to an aqueous solution of $\mathrm{BF}_{3} \cdot \mathrm{Et}_{2} \mathrm{O}$, using solid $\mathrm{BPO}_{4}$ at $-3.5 \mathrm{ppm}$ as a secondary standard. Additional ${ }^{11} \mathrm{~B}$ MAS NMR data were measured at $16.4 \mathrm{~T}$ using a Bruker Avance III spectrometer and at $5.64 \mathrm{~T}$ using a Agilent DD2 spectrometer, using similar acquisition parameters. Fitting of all ${ }^{11}$ B MAS NMR spectra has been performed using the DMfit software ${ }^{31}$ in order to quantify structural species in the glasses, utilizing "Q MAS 1/2" and Gauss/Lorentz function program modules for fitting the peaks of 3- and 4-coordinated boron species, respectively. The fraction of four-coordinated boron species, $N_{4}$, has been calculated from the relative peak areas, with a small correction due to the overlapping satellite transition of the 4 -fold coordinated boron peak. ${ }^{32}$

${ }^{23} \mathrm{Na}$ MAS NMR spectra have been measured on a Bruker Avance III 600 spectrometer. Spectra were acquired on samples rotating at $15.0 \mathrm{kHz}$, using short pulses of $1.0 \mu$ s length, with a relaxation delay of 1s. The data has been fit using the Czjzek distribution model implemented in the DMfit software, considering a wide distribution of quadrupolar coupling constants $C_{\mathrm{Q}}$, resulting in an average value $\left\langle C_{\mathrm{Q}}\right\rangle$ and an average isotropic chemical shift $\left\langle\delta_{\mathrm{iso}}{ }^{23} \mathrm{Na}\right\rangle$.

${ }^{29}$ Si MAS NMR spectra have been obtained on an Agilent DD2 spectrometer interfaced with a 5.64 T magnet. Samples were rotated within spinners of $7.5 \mathrm{~mm}$ outer diameter at a frequency of $5.0 \mathrm{kHz}$. Spectra were acquired with $90^{\circ}$ pulses of $4.5 \mu$ s length, $100-150$ scans, separated by a relaxation delay of $300 \mathrm{~s}$.

Unpolarized Raman spectra have been collected at room temperature over the range of 300 to $1600 \mathrm{~cm}^{-1}$ with a precision of $\pm 1 \mathrm{~cm}^{-1}$, using an inVia Renishaw confocal Raman spectrometer equipped with a CCD detector. The excitation source was the $532 \mathrm{~nm}$ line of a green diode laser 
operating at $500 \mathrm{~mW}$. The measurements were performed at different positions on the sample surface to ascertain the sample homogeneity. The raw spectra were corrected for temperature and frequency-dependent scattering intensity, ${ }^{33-37}$ followed by a linear baseline fit. The corrected spectra were then normalized to the integrated signal intensity and deconvoluted into individual components using the OriginPro $2018 \mathrm{~b}$ software.

\subsection{Thermal analysis}

Glass transition temperatures, $\mathrm{T}_{\mathrm{g}}$, have been measured on powdered samples (particle size range of 0.85 to $1 \mathrm{~mm}$ ) by Differential Scanning Calorimetry (DSC; Netzsch simultaneous thermal analyzer, STA-449F Jupiter). The samples were loaded in Pt-Rh (10 wt.\% Rh) pans, covered with a Pt lid, and heated in air from room temperature to $1000^{\circ} \mathrm{C}$ at a rate of $10^{\circ} \mathrm{C} / \mathrm{min}$. An empty Pt-Rh pan was used as a reference. The $T_{\mathrm{g}}$ values reported are averages of at least three measurements.

\section{Results}

\subsection{Sulfur solubility}

All the sulfur-free baseline glasses synthesized in the present study are XRD amorphous (Figure $\mathrm{S} 1(\mathrm{a}-\mathrm{c})$ ) and optically transparent (Figure $\mathrm{S} 2-\mathrm{S} 4$ ). To estimate $\mathrm{SO}_{3}$ solubility, sodium sulfate was added stepwise to the baseline glasses (starting from $0.5 \mathrm{~mol} . \% \mathrm{SO}_{3}$ ) maintaining the total sodium content constant (see section 2.2), until it supersaturates in the melt and appears as a white salt layer on the glass surface. The highest concentration of $\mathrm{SO}_{3}$ which dissolves in a given quantity (70 g) of glass without altering its amorphous nature (as analyzed by XRD analysis) is 
considered to be its (experimental) $\mathrm{SO}_{3}$ solubility. Once the $\mathrm{SO}_{3}$ solubility limit has been reached, the excess sulfate tends to partition out of the melt in the form of a salt and floats on the melt surface. Upon quenching the melt, the salt layer forms a white powder that sticks to the surface of the transparent and XRD amorphous glass (Figures $\mathrm{S} 2-\mathrm{S} 4$ ). All the $\mathrm{SO}_{3}$-containing glasses (below the solubility limit) are XRD amorphous, (Figure S1-d). The XRD analysis of the salt layer (Figure S1-d) reveals the formation of $\mathrm{Na}_{2} \mathrm{SO}_{4}$ (PDF\# 97-006-3077) as the only crystalline phase in all the three series of glasses.

The compositional analysis of the sulfur-containing glasses has been performed only for the compositions exhibiting the (experimental) solubility limit of $\mathrm{SO}_{3}$. Therefore, the $\mathrm{SO}_{3}$ concentrations reported in Table 1 should be considered as the solubility limit of $\mathrm{SO}_{3}$ in the respective glasses. The chemical analyses of the sulfur-free baseline glasses are in good agreement with the batched compositions (Figure 1 and Table S1) suggesting minimal volatilization of $\mathrm{Na}_{2} \mathrm{O}$ or $\mathrm{B}_{2} \mathrm{O}_{3}$ from the glass melts. Therefore, all the structure-property correlations discussed in this study should be considered as a manifestation of the impact of $\mathrm{SO}_{3}$ addition to the glasses.

Table 1. Glass compositions and experimentally determined maximum $\mathrm{SO}_{3}$ solubility in the investigated glasses.

\begin{tabular}{ccccccc}
\hline Glass & {$\left[\mathbf{N a}_{\mathbf{2}} \mathbf{O}\right]$} & {$\left[\mathbf{B}_{\mathbf{2}} \mathbf{O}_{\mathbf{3}}\right]$} & {$\left[\mathbf{S i O}_{\mathbf{2}}\right]$} & $\mathbf{R}$ & $\mathbf{K}$ & {$\left[\mathbf{m o l . \%} \mathbf{\%} \mathbf{S O}_{\mathbf{3}}\right]$} \\
\hline NB-15 & 15 & 45 & 40 & 0.33 & 0.88 & - \\
NB-25 & 25 & 35 & 40 & 0.71 & 1.14 & $0.90 \pm 0.01$ \\
NB-30 & 30 & 30 & 40 & 1 & 1.33 & $1.70 \pm 0.03$ \\
NB-35 & 35 & 25 & 40 & 1.4 & 1.6 & $1.93 \pm 0.03$ \\
NB-40 & 40 & 20 & 40 & 2 & 2 & $2.82 \pm 0.02$ \\
SB-75 & 25 & 75 & 0 & 0.33 & 0 & - \\
SB-60 & 25 & 60 & 15 & 0.42 & 0.25 & $0.38 \pm 0.03$ \\
SB-45 & 25 & 45 & 30 & 0.55 & 0.67 & $0.87 \pm 0.02$ \\
SB-30 & 25 & 30 & 45 & 0.83 & 1.5 & $0.96 \pm 0.02$ \\
SB-15 & 25 & 15 & 60 & 1.67 & 4 & - \\
SB-0 & 25 & 0 & 75 & - & - & - \\
\hline
\end{tabular}




\begin{tabular}{ccccccc}
\hline NS-20 & 20 & 15 & 65 & 1.33 & 4.33 & - \\
NS-25 & 25 & 15 & 60 & 1.67 & 4 & - \\
NS-30 & 30 & 15 & 55 & 2 & 3.67 & $1.93 \pm 0.02$ \\
NS-35 & 35 & 15 & 50 & 2.33 & 3.33 & $2.88 \pm 0.03$ \\
NS-40 & 40 & 15 & 45 & 2.67 & 3 & $3.3 \pm 0.02$ \\
NS-45 & 45 & 15 & 40 & 3 & 2.67 & $3.86 \pm 0.02$ \\
\hline
\end{tabular}

As shown in Table 1, the $\mathrm{SO}_{3}$ solubility of the investigated glasses ranges from 0.46 to 4.89 wt\%. The glasses with $\mathrm{SO}_{3}$ solubility less than 0.5 mol.\% were not studied further. Although the $\mathrm{SO}_{3}$ concentration in these glasses was above the detection limit of ICP-OES, the large RSD (relative standard deviation) value $(\sim 18 \%)$ did not allow us to measure the $\mathrm{SO}_{3}$ content in these glasses within the range of experimental certainty.

In the NB- $x$ series of glasses, $\mathrm{SO}_{3}$ solubility increases linearly with increasing $R$ (Figure S5a). In the glasses with varying $\mathrm{SiO}_{2}-$ to $-\mathrm{B}_{2} \mathrm{O}_{3}$ ratio $(\mathrm{SB}-y)$, the $\mathrm{SO}_{3}$ solubility in glasses near the $\mathrm{B}_{2} \mathrm{O}_{3}$-rich end, i.e., $25 \mathrm{Na}_{2} \mathrm{O}-75 \mathrm{~B}_{2} \mathrm{O}_{3}$ (SB-75) and $25 \mathrm{Na}_{2} \mathrm{O}-15 \mathrm{SiO}_{2}-60 \mathrm{~B}_{2} \mathrm{O}_{3}$ (SB-60) (mol.\%), is $\leq 0.5$ mol.\% $(0.46 \mathrm{wt} . \%)$ despite their low melting temperatures $\left(<1000{ }^{\circ} \mathrm{C}\right)$. On the other hand, $\mathrm{SO}_{3}$ solubility in the $\mathrm{SiO}_{2}$-rich end members, i.e., $25 \mathrm{Na}_{2} \mathrm{O}-75 \mathrm{SiO}_{2}(\mathrm{SB}-0)$ and $25 \mathrm{Na}_{2} \mathrm{O}-$ $15 \mathrm{~B}_{2} \mathrm{O}_{3}-60 \mathrm{SiO}_{2}(\mathrm{SB}-15)$ (mol.\%), is zero owing to their high melting temperatures (1450-1600 ${ }^{\circ} \mathrm{C}$ ), leading to sulfur volatilization. Preliminary results, ${ }^{38}$ indicate that the rate of sulfur volatilization from the melt increases rapidly at temperatures $>1300{ }^{\circ} \mathrm{C}$, resulting in complete loss of sulfur near $1350{ }^{\circ} \mathrm{C}$. Similar results pertaining to sulfur volatilization from the glass melts have also been reported in the literature. ${ }^{18}$ For the glasses with $\mathrm{SiO}_{2}\left(\right.$ or $\left.\mathrm{B}_{2} \mathrm{O}_{3}\right)$ content varying between 30-45 mol.\%, the $\mathrm{SO}_{3}$ solubility shows an incremental change by a factor of 1.13 with an increase in $K$ from 0.67 to 1.5 (Table 1).

In the glasses from NS series, the $\mathrm{SO}_{3}$ solubility is highly composition dependent. It is zero for glass $25 \mathrm{Na}_{2} \mathrm{O}-15 \mathrm{~B}_{2} \mathrm{O}_{3}-60 \mathrm{SiO}_{2}$ (NS-25) as all the sulfur volatilizes from the melt due to the 
high melting temperature $\left(>1400{ }^{\circ} \mathrm{C}\right)$. An increase in $\mathrm{Na}_{2} \mathrm{O} / \mathrm{SiO}_{2}$ molar ratio from 0.54 to 1.125 results in an increase in the $\mathrm{SO}_{3}$ solubility by a factor of $\sim 2$ (Figure S5-b). Among all the glasses investigated in the present study, the glass with composition (mol.\%) $45 \mathrm{Na}_{2} \mathrm{O}-15 \mathrm{~B}_{2} \mathrm{O}_{3}-40 \mathrm{SiO}_{2}$ (NS-45) exhibits the highest $\mathrm{SO}_{3}$ solubility of 3.86 mol.\%.

\subsection{Structure of the baseline glasses}

\subsubsection{Raman spectroscopy}

\subsubsection{Band assignment}

Figure 2 presents the Raman spectra of the sulfur-free baseline glasses. For the convenience of readers, the Raman spectra have been divided into three frequency regions, as described below.

(1) Low frequency region (300 to $\left.850 \mathrm{~cm}^{-1}\right)$

In this region, the bands between 300 and $500 \mathrm{~cm}^{-1}$ have been assigned to mixed stretching and bending modes of $\mathrm{Si}-\mathrm{O}-\mathrm{Si}$ and $\mathrm{Si}-\mathrm{O}-\mathrm{B}$ linkages whose frequency increases with increasing alkali content. ${ }^{39-42}$ The frequency region of $550-850 \mathrm{~cm}^{-1}$ corresponds to the breathing modes of metaborate units, ${ }^{43}$ and other borate- and borosilicate-ring unit groups. ${ }^{44-46}$ In this region, the peak around $630 \mathrm{~cm}^{-1}$ corresponds to the breathing mode of $\mathrm{Si}-\mathrm{O}-\mathrm{B} \emptyset_{4}$ linkages $(\varnothing$ denotes the bridging oxygen) in danburite-like units, ${ }^{37,47}$ and the band around $700 \mathrm{~cm}^{-1}$ corresponds to the breathing vibrations of metaborate units. ${ }^{43}$ The band at $770 \mathrm{~cm}^{-1}$ has been assigned to the symmetric breathing vibrations of six-membered borate rings containing one $\mathrm{B} \emptyset_{4}$ unit, and this band shifts towards the lower frequency side to $750 \mathrm{~cm}^{-1}$ for the borate rings containing two $\mathrm{B} \emptyset_{4}$ units. $^{48,49}$ Further, the band around $806 \mathrm{~cm}^{-1}$ corresponds to the vibration of three-coordinated $\mathrm{B} \emptyset_{3}$ units in the boroxol rings. ${ }^{50-52}$ For convenience the $\mathrm{B} \emptyset_{4}$ and $\mathrm{B} \emptyset_{3}$ units are henceforth labeled $\mathrm{B}^{4}$ and $\mathrm{B}^{3}$, where the superscript denotes the number of bridging oxygen atoms. 
(2) Mid-frequency region (850 to $1200 \mathrm{~cm}^{-1}$ )

This frequency region arises mainly due to the stretching vibrations of $\mathrm{Si}-\mathrm{O}$ bonds in the $\mathrm{Si}^{n}$ units of the glass structure. Here $n$ is the number of bridging oxygen atoms per Si atom ranging from 1 to 4 . The bands centered around $880 \mathrm{~cm}^{-1}, 950 \mathrm{~cm}^{-1}$, and $1070-1080 \mathrm{~cm}^{-1}$ represent $\mathrm{Si}-\mathrm{O}^{-}$ stretching vibrations of $\mathrm{Si}^{1}, \mathrm{Si}^{2}$ and $\mathrm{Si}^{3}$ units, respectively, while the high frequency band between $1100-1200 \mathrm{~cm}^{-1}$ has been previously identified to be attributable to vibrations involving the fully polymerized $\mathrm{Si}^{4}$ units. ${ }^{19,33,40,51}$ The assignment of the band between 1000 and $1050 \mathrm{~cm}^{-}$ ${ }^{1}$ is uncertain. It has been attributed to the stretching mode of $\mathrm{Si}-\varnothing$ in the $\mathrm{Si}$ tetrahedra $\left(\mathrm{Si}^{1}, \mathrm{Si}^{2}\right.$,

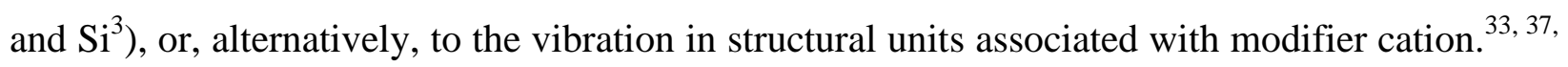
53

\section{(3) High frequency borate stretching region (1200 to $1600 \mathrm{~cm}^{-1}$ )}

This high frequency region represents the stretching vibrations of symmetric $\mathrm{B}^{3}$ units and asymmetric three-coordinated boron species (such as $\mathrm{B}_{2} \mathrm{O}^{-}$groups linked to two bridging and one non-bridging $\mathrm{O}$-atoms, henceforth denoted by $\mathrm{B}^{2}$ units, which are possibly linked to form chains. ${ }^{47,54}$ In this region, the lower-frequency peak around $1400 \mathrm{~cm}^{-1}$ is assigned to $\mathrm{B}^{2}$ units linked to $\mathrm{B}^{4}$ units, while the component near $1470 \mathrm{~cm}^{-1}$ is assigned to $\mathrm{B}^{2}$ units linked to $\mathrm{B}^{3}$ groups. ${ }^{37,47,50}$ Yano et al. ${ }^{44-46}$ have assigned the component close to $1510 \mathrm{~cm}^{-1}$ to the stretching modes of $\mathrm{B}^{3}$ units in boroxol rings. A small peak around $1550 \mathrm{~cm}^{-1}$ is observed in all the glasses and has been attributed to the molecular oxygen present in the atmosphere surrounding the glass sample while recording Raman spectra. ${ }^{55}$

The deconvolution of Raman spectra has been performed using the procedure described by Manara et al. ${ }^{37}$ and Le Losq et al. ${ }^{33}$ and is given in the Supporting Materials section. Despite of the deconvolutions provided, these spectra are used only for the qualitative interpretation of the 
glass structure and could not be used for the quantitative interpretation of the populations of silicate and borate units.

\subsubsection{Structural analysis based on band assignment and spectral fitting}

Based on the assignment and fitting of bands in the Raman spectra, the following details about the evolution in the short-to-intermediate range ordering in the structure of the investigated glasses, as a function of their composition, have been deduced.

(1) NB-x glasses

For glasses of the NB- $x$ series, Figures $2 \mathrm{a}, 2 \mathrm{~b}$, and S6 suggest the following structural trends with increasing $R$ :

I. The band centered around $500 \mathrm{~cm}^{-1}$, corresponding to the mixed stretching, and bending vibrations of $\mathrm{Si}-\mathrm{O}-\mathrm{Si}$ bonds, shifts towards higher frequencies.

II. The intensity of the band at $\square 630 \mathrm{~cm}^{-1}$ increases, passes a maximum at $R=0.71$ (NB-25) followed by a subsequent decrease. The increase in the intensity of the peak in glasses with $R \leq$ 0.7 can be attributed to the increasing molar concentration of $\mathrm{B}^{4}$ units (as also observed in ${ }^{11} \mathrm{~B}$ MAS NMR, see section 3.2.2) and their tendency to connect with $\mathrm{Si}^{n}$ units, ${ }^{26}$ thus, resulting in an increased concentration of $\mathrm{Si}-\mathrm{O}-\mathrm{B}^{4}$ linkages in the glass structure. The decrease in the $\mathrm{Si}-\mathrm{O}-\mathrm{B}^{4}$ linkages in the glasses with $R>0.71$ may be attributed to the increasing fraction of threecoordinated borate units associated with NBOs (i.e., $\mathrm{B}^{2}$ units) at the expense of $\mathrm{B}^{4}$ units. This is evident from the shifting of the $770 \mathrm{~cm}^{-1}$ band towards lower frequency (up to $\square 748 \mathrm{~cm}^{-1}$ ) with reduced intensity, and simultaneous increasing intensities of bands at $\square 690 \mathrm{~cm}^{-1}$ (B $\mathrm{B}^{2}$ units) and $1470 \mathrm{~cm}^{-1}$ (corresponding to $\mathrm{B}^{2}-\mathrm{B}^{3}$ linkages). ${ }^{37,56}$ These results are in agreement with the ${ }^{11} \mathrm{~B}$ MAS NMR results, as the fraction of four-coordinated boron (as deduced from ${ }^{11} \mathrm{~B}$ MAS NMR spectra) is the highest in the glass at $R=0.71$ (Table 2). 
III. The band at $\sim 806 \mathrm{~cm}^{-1}$, corresponding to the symmetric stretching mode of the boroxol rings, appears in the glass NB-15 (with $R=0.33$ ) and diminishes with an increase in $R$, indicating a decrease in the concentration of boroxol rings in the glass structure. This structural feature is also supported by the gradual decrease in the intensity of the band at $\sim 1510 \mathrm{~cm}^{-1} .37,44-46$

IV. The gradual decrease in the concentration of $\mathrm{B}^{2}-\mathrm{B}^{4}$ linkages with increasing $R$, as indicated by a decreasing intensity of the band near $\sim 1400 \mathrm{~cm}^{-1}$, further supports the decreasing concentration of $\mathrm{B}^{4}$ units, and their low tendency to bind with other anionic borate species. 

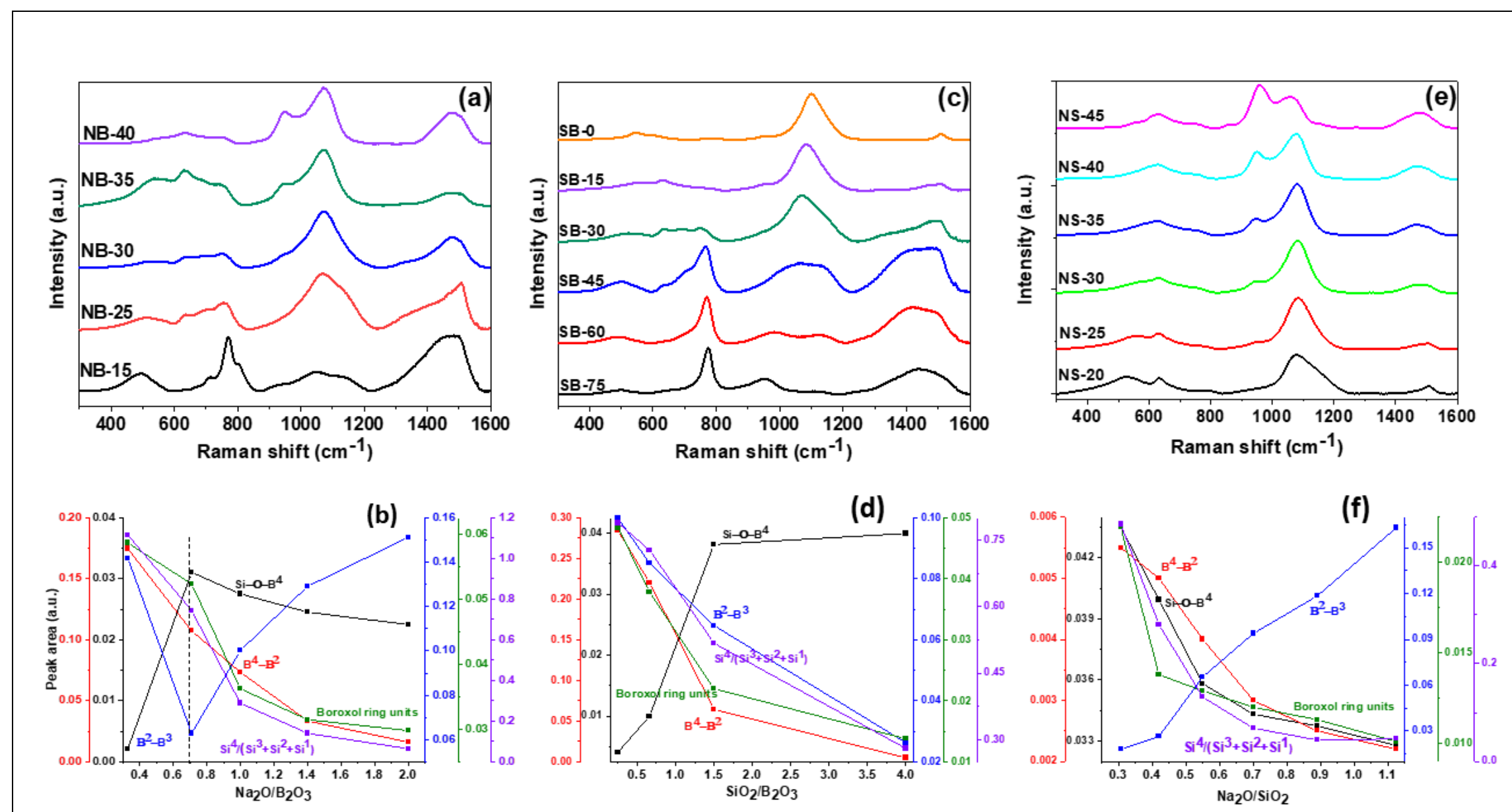

Figure 2. Raman spectra of (a) NB- $x$, (b) SB-y, and (c) NS- $z$ series of sulfur-free baseline glasses. The corresponding variations of structural linkages are shown as (b), (d) and (f). 
V. The steep increase in the concentration of $\mathrm{B}^{2}-\mathrm{B}^{3}$ linkages in the glasses with $R \geq 0.71$, as inferred from the increase in intensity of $\sim 1470 \mathrm{~cm}^{-1}$ band, ${ }^{37,43,47}$ can be attributed to the cumulative decrease in the concentration of $\mathrm{Si}-\mathrm{O}-\mathrm{B}^{4}, \mathrm{~B}^{2}-\mathrm{B}^{4}$, and boroxol units in the glass structure due to increase in the $\mathrm{Na}_{2} \mathrm{O}$ content. The increase in concentration of $\mathrm{B}^{2}$ units in this composition region is also indicated by the ${ }^{11}$ B MAS NMR spectra of these glasses (see section 3.2.2).

VI. With reference to the structural evolution in the silicate network in these glasses, the spectra of NB and NS glasses show a steep rise in the concentration of the $\mathrm{Si}^{3}$ and $\mathrm{Si}^{2}$ units $(\sim 1070$ and $950 \mathrm{~cm}^{-1}$, respectively) with increasing $\mathrm{R}$. This change in intensity, together with the observed shift in the $500 \mathrm{~cm}^{-1}$ band towards higher frequency (as discussed in point I), indicates that the degree of polymerization in silicate network decreases with increasing $R$, as evident from Figure $2 \mathrm{~b} .{ }^{37,47}$

(2) SB-y glasses

Figure $2 \mathrm{c}$ and $2 \mathrm{~d}$ present the Raman spectra and corresponding structural linkages in the SB$y$ series of glasses, respectively, while the deconvoluted Raman spectra are shown in Figure S7. The structural information derived from the Raman spectra of these glasses has been summarized below.

I. The Raman spectrum of sodium silicate glass (SB-0) exhibits a characteristic band at $\square 542$ $\mathrm{cm}^{-1}$ with a shoulder at $596 \mathrm{~cm}^{-1}$ (associated with combinations of bending and stretching modes involving Si-O-Si linkages), a low intensity band $\square 785 \mathrm{~cm}^{-1}$ (representing $\mathrm{Si}-\mathrm{O}-\mathrm{Si}$ bending modes), a small hump around $949 \mathrm{~cm}^{-1}$ ( $\mathrm{Si}^{2}$ units) and a high intensity band at $\square 1100 \mathrm{~cm}^{-1}$ ( $\mathrm{Si}^{3}$ units). ${ }^{33,39,41,57}$ In agreement with the literature, ${ }^{44,48,51}$ the spectrum of sodium borate (SB-75) glass exhibits the characteristic peaks at $498,773,950,1115 \mathrm{~cm}^{-1}$ and a cupola shaped band 
centered around $1444 \mathrm{~cm}^{-1}$. The band around $498 \mathrm{~cm}^{-1}$ corresponds to the $\mathrm{B}-\mathrm{O}-\mathrm{B}$ stretching vibration of $\mathrm{B}^{4}$ units. $^{48,52}$ The prominent peak at $773 \mathrm{~cm}^{-1}$ corresponds to the symmetric breathing vibrations of the six-membered borate rings containing one $\mathrm{B} \emptyset_{4}$ unit as identified in the NB- $x$ series. The peak around $950 \mathrm{~cm}^{-1}$ is associated with pentaborate units and the peak at $1115 \mathrm{~cm}^{-1}$ indicates the presence of diborate units in the glass network. ${ }^{48}$ The broad band centered around $1444 \mathrm{~cm}^{-1}$ in the high frequency region represents the stretching vibrations $\mathrm{B}^{2}$ units linked to $\mathrm{B}^{4}$ units and $\mathrm{B}^{2}$ units linked to $\mathrm{B}^{3}$ units.

II. The substitution of $\mathrm{SiO}_{2}-$ for $-\mathrm{B}_{2} \mathrm{O}_{3}$ in the glasses reveals a band at $\sim 493 \mathrm{~cm}^{-1}$ corresponding to $\mathrm{Si}-\mathrm{O}-\mathrm{Si}$ bending vibrations, and a broad band in the frequency range of $850-1200 \mathrm{~cm}^{-1}$ associated with $\mathrm{Si}-\mathrm{O}$ symmetric stretching vibrations of $\mathrm{Si}^{\mathrm{n}}$ units. An increase in $K$ results in an increase in the peak area of $\mathrm{Si}-\mathrm{O}$ symmetric stretching region along with a concomitant decrease in the peak area corresponding to the high frequency borate stretching region $\left(1250-1600 \mathrm{~cm}^{-1}\right){ }^{47}$

III. The intensity of the band $\sim 630 \mathrm{~cm}^{-1}$ increases steeply with increasing $K$ up to 1.5 , and then changes little up to $K=4$. The initial increase is attributed to the increasing $\mathrm{SiO}_{2}$ content in the glasses and their association with $\mathrm{B}^{4}$ units. The increase in the $\mathrm{Si}-\mathrm{O}-\mathrm{B}^{4}$ linkages with an increase in $K$ is also illustrated by the ${ }^{11}$ B MAS NMR spectra (see section 3.2.2).

IV. The intensity of the $\mathrm{Si}^{3}\left(\square 1070 \mathrm{~cm}^{-1}\right)$ band increases with increasing $K$, reflecting the increase in silica content. ${ }^{47}$ The intensity of the band at $950 \mathrm{~cm}^{-1}$ attributed to the $\mathrm{Si}^{2}$ units appears very low throughout the series. Unlike the situation in the NB- $x$ and NS- $z$ glasses (see below), the Raman data does not give a clear evidence of dramatic changes in the degree of silicate polymerization with increasing $K^{37}$

According to Dell-Yun-Bray (DYB) model, ${ }^{22-24}$ the silicate network in the $\mathrm{Na}_{2} \mathrm{O}-\mathrm{B}_{2} \mathrm{O}_{3}-\mathrm{SiO}_{2}$ glasses should be fully polymerized up to $K=0.67$, as $\mathrm{Na}^{+}$is supposed to solely act as the charge 
compensator for the $\mathrm{B}^{4}$ units. Nevertheless, this is not the case in the present study, as the presence of $\mathrm{Si}^{3}$ units in the glasses SB-60 $(K=0.25)$ and $\mathrm{SB}-45(\mathrm{~K}=0.67)$ is evident from the presence of band near $1070 \mathrm{~cm}^{-1}$ in their Raman spectra (Figure 2c). This conclusion is further corroborated by the ${ }^{29} \mathrm{Si}$ MAS NMR data reported in the section 3.2.3. Our results are more consistent with Bunker et al., ${ }^{58}$ Wang et al., ${ }^{59}$ and Martens and Müller-Warmuth, ${ }^{60}$ who demonstrated the formation of NBOs in silicate and borate network in the glasses from Region I and II of the DYB model. The initial subtle decrease in the relative area ratio $\frac{S i^{4}}{S i^{1}+S i^{2}+S i^{3}}$ with $K$ $\left(\leq 0.67\right.$ for SB-60) (Figure 2d) is attributed to the fact that although $\mathrm{Na}^{+}$predominantly interacts with the borate network, some $\mathrm{Na}^{+}$interacts with the silicate network and facilitates creation of NBOs. ${ }^{58}$ In the region where $K>0.67$, the relative ratio $\frac{S i^{4}}{S i^{1}+S i^{2}+S i^{3}}$ decreases abruptly with increasing $K$ (up to 4), due to the increasing concentration of excess $\mathrm{Na}^{+}$(remaining after charge compensation of the $\mathrm{B}^{4}$ units) available to create NBOs in the silicate network. This observation is consistent with DYB model, ${ }^{24}$ according to which $\mathrm{Na}^{+}$acts as a modifier in Regions III and IV of the composition diagram, i.e., in the glasses SB-30 and SB-15, respectively, as shown in Figure 1.

V. The decreasing concentration of boroxol rings, $\mathrm{B}^{2}-\mathrm{B}^{4}$, and $\mathrm{B}^{2}-\mathrm{B}^{3}$ linkages is due to the decreasing $\mathrm{B}_{2} \mathrm{O}_{3}$ content in the glasses. The ${ }^{11} \mathrm{~B}$ MAS NMR analysis (section 3.2.2) suggests that the contribution of $\mathrm{B}^{2}$ units to the borate inventory remains relatively low within the SB- $y$ series. (3) NS-z glasses

Figure 2e presents the Raman spectra of NS-z glasses with characteristic bands for danburitelike ring structures $\left(\square 630 \mathrm{~cm}^{-1}\right)$, borate rings associated with two $\mathrm{B}^{4}$ units $\left(750 \mathrm{~cm}^{-1}\right), \mathrm{Si}^{2}(\square 950$ $\left.\mathrm{cm}^{-1}\right), \mathrm{Si}^{3}\left(\square 1070 \mathrm{~cm}^{-1}\right)$, and $\mathrm{B}^{2}$ units $\left.\left(1470 \mathrm{~cm}^{-1}\right)\right)$. The corresponding structural linkages and 
deconvoluted Raman spectra are shown in Figures $2 \mathrm{f}$ and S8, respectively. The following structural information can be derived from the Raman spectra of these glasses.

I. As $\mathrm{Na}_{2} \mathrm{O} / \mathrm{SiO}_{2}$ ratio increases from 0.31 to 1.12 , the intensity of the band $\sim 630 \mathrm{~cm}^{-1}$ decreases while that of $\sim 1470 \mathrm{~cm}^{-1}$ band increases, indicating the decrease in $\mathrm{Si}-\mathrm{O}-\mathrm{B}^{4}$ linkages and an increase in $\mathrm{B}^{2}-\mathrm{B}^{3}$ linkages in the glass structure. The decrease in the $\mathrm{Si}-\mathrm{O}-\mathrm{B}^{4}$ linkages with increasing $\mathrm{Na}_{2} \mathrm{O} / \mathrm{SiO}_{2}$ ratio is due to the increasing concentration of excess $\mathrm{Na}^{+}$available favoring the formation of $\mathrm{B}^{2}$ units in lieu of $\mathrm{B}^{4}$ groups This trend is evident from the increasing intensity of the band $\sim 1470 \mathrm{~cm}^{-1}$, and also in agreement with the ${ }^{11} \mathrm{~B}$ MAS NMR results (section 3.2.2).

II. Regarding the silicate network in these glasses, the intensity of $\mathrm{Si}^{2}$ band increases at the expense of the $\mathrm{Si}^{3}$ bands as the $\mathrm{Na}_{2} \mathrm{O} / \mathrm{SiO}_{2}$ ratio increases, documenting the depolymerization in the silicate network. This is attributed to the increasing $\mathrm{Na}_{2} \mathrm{O} / \mathrm{SiO}_{2}$ ratio, furnishing an increased amount of modifier oxide available for NBO formation.

III. The decreasing intensity of the band $\sim 1400 \mathrm{~cm}^{-1}\left(\mathrm{~B}^{4}-\mathrm{B}^{2}\right.$ linkages), coupled with the increasing intensity of the band $\sim 1470 \mathrm{~cm}^{-1}$ band $\left(\mathrm{B}^{2}-\mathrm{B}^{3}\right.$ linkages), as shown in Figure $2 \mathrm{f}$, reflects the tendency of anionic borate formation in the form of $\mathrm{B}^{2}$ rather than $\mathrm{B}^{4}$ units in the glasses with high $\mathrm{R}$ values.

Thus, the increasing $\mathrm{Na}_{2} \mathrm{O} / \mathrm{SiO}_{2}$ ratio in the NS- $z$ series of glasses induces strong depolymerization in their silicate and borate networks. The observed depolymerization of NS- $z$ glasses is consistent with DYB model ${ }^{24}$ and Bunker et al. ${ }^{58}$ which predicts the formation of NBOs in the silicate as well as borate network in Region 4 of the composition diagram (Figure 1).

\subsection{2 ${ }^{11} B$ MAS NMR}


Figure 3 shows the ${ }^{11} \mathrm{~B}$ MAS NMR spectra of all the baseline glasses. They reveal two salient features: (i) a broad, structured resonance in the chemical shift region 10-20 ppm, attributed to three-coordinated boron (B(II)) sites, and (ii) a relatively narrow peak around $0 \mathrm{ppm}$, corresponding to four-coordinated boron (B(IV)) sites. ${ }^{8,25,26,61}$ The lineshapes attributed to the $\mathrm{B}(\mathrm{III})$ units are affected by the interaction of the ${ }^{11} \mathrm{~B}$ nuclear electric quadrupole moment with the strong local electric field gradients created at the boron nucleus by this trigonal environment. In this case, the effects on the ${ }^{11} \mathrm{~B}$ MAS NMR spectra must be calculated by second-order perturbation theory, resulting in only partially narrowed MAS NMR spectra, from which the interaction parameters, isotropic chemical shift, $\delta_{\text {iso }}{ }^{c s}$, quadrupolar coupling constant $C_{\mathrm{Q}}$, and the electric field gradient asymmetry parameter, $\eta_{\mathrm{Q}}$, can be determined by simulation. In the present case, the simplest approach towards a successful lineshape deconvolution conducted at three different magnetic field strengths $(16.4 \mathrm{~T}, 14.1 \mathrm{~T}$, and 5.64 $\mathrm{T})$ assumes the presence of two distinct B(III) components and up to two distinct B(IV) components (see Figure S9-14 for some examples). Extensive simulation studies based on different models indicate that there are multiple ways of getting acceptable two-component fits for the signal belonging to the $\mathrm{B}(\mathrm{III})$ units. The results of the lineshape analysis summarized in Table 2 represent the two-component deconvolution model yielding the most consistent results at different field strengths. Here we would like to highlight that the asymmetry parameters listed in Table 2 should be viewed as apparent values, which are also influenced by the existence of distributions of isotropic chemical shifts and $\mathrm{C}_{\mathrm{Q}}$-values. Nonetheless, since the scientific outcomes of our study depend only on an accurate determination of $N_{4}$ values, and all the deconvolution models considered in this study yield similar $N_{4}$ values within experimental error, the conclusions of our work remain unaffected by this issue. In all the glasses with $R<1.5$, the isotropic chemical shifts of the $\mathrm{B}$ (III) 
components are found near $18.2 \pm 0.4 \mathrm{ppm}$, labeled B(III)-1, and $15.8 \pm 0.4 \mathrm{ppm}$, labeled B(III)2. Following the arguments presented previously, site B(III)-1 may be identified with B(III) units contained within ring structures, and B(III)-2 may be associated with non-ring structures, and/or

B(III) species linked to silicon. $\quad$ For



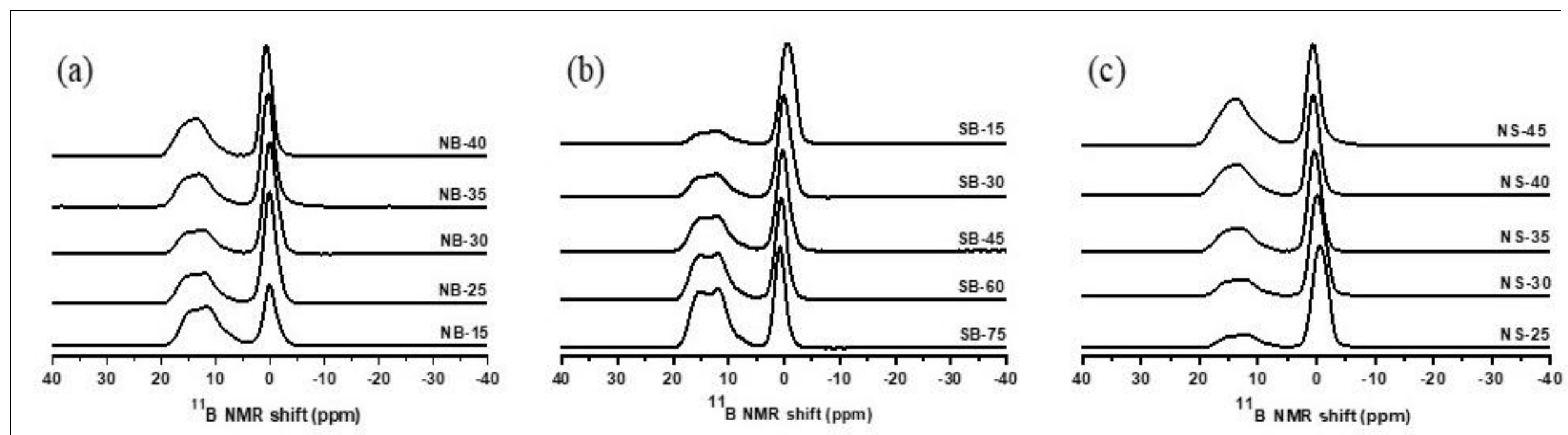

Figure 3. ${ }^{11}$ B MAS NMR spectra of sulfur-free baseline glasses. 
Table 2. Fitting parameters of ${ }^{11} \mathrm{~B}$ MAS NMR in the studied glasses, including fraction of each species $f( \pm 1 \%)$, isotropic chemical shift $\delta_{\text {iso }}{ }^{\text {cs }}( \pm 0.5 \mathrm{ppm})$, quadrupolar coupling constant, $C_{\mathrm{Q}}( \pm 0.10 \mathrm{MHz}), \eta_{\mathrm{Q}}( \pm 0.05)$, and overall $N_{4}$ values $( \pm 1 \%)$. For the latter, values independently measured at $5.7 \mathrm{~T}$ are listed in brackets.

\begin{tabular}{|c|c|c|c|c|c|c|c|c|c|c|c|c|c|}
\hline \multirow[b]{2}{*}{$\begin{array}{c}\text { Sample } \\
\text { ID }\end{array}$} & \multicolumn{4}{|c|}{ B(III) -1 } & \multicolumn{4}{|c|}{ B(III) -2 } & \multicolumn{2}{|c|}{ B(IV)-1 } & \multicolumn{2}{|c|}{ B(IV)-2 } & \multirow[b]{2}{*}{$N_{4}$} \\
\hline & $f(\%)$ & $\begin{array}{c}\delta_{\text {iso }}^{\mathrm{cs}} \\
(\mathbf{p p m})\end{array}$ & $\begin{array}{c}\mathrm{C}_{\mathrm{Q}} \\
(\mathrm{MHz})\end{array}$ & $\eta_{Q}$ & $f(\%)$ & $\begin{array}{c}\delta_{\text {iso }}^{\text {cs }} \\
(\mathbf{p p m})\end{array}$ & $\begin{array}{c}\mathrm{C}_{\mathrm{Q}} \\
(\mathrm{MHz})\end{array}$ & $\eta_{Q}$ & $f(\%)$ & $\begin{array}{c}\delta_{\text {iso }}^{\text {cs }} \\
(\mathbf{p p m})\end{array}$ & $f(\%)$ & $\begin{array}{c}\delta_{\text {iso }}^{\text {cs }} \\
(\mathbf{p p m})\end{array}$ & \\
\hline NB-15 & 36 & 17.8 & 2.60 & 0.30 & 27 & 15.9 & 2.61 & 0.42 & 37 & -0.04 & & & $0.37[0.37]$ \\
\hline NB-25 & 32 & 18.3 & 2.60 & 0.34 & 7 & 15.5 & 2.44 & 0.31 & 41 & 0.43 & 20 & -1.14 & $0.61[0.61]$ \\
\hline NB-30 & 28 & 18.4 & 2.59 & 0.35 & 6 & 15.5 & 2.45 & 0.30 & 43 & 0.42 & 23 & -1.18 & 0.66 \\
\hline NB-35 & 29 & 18.5 & 2.57 & 0.32 & 13 & 16.1 & 2.58 & 0.24 & 43 & 0.37 & 15 & -1.5 & 0.58 \\
\hline NB-40 & 28 & 18.5 & 2.35 & 0.38 & 21 & 17.4 & 2.37 & 0.66 & 51 & 0.58 & & & 0.51 \\
\hline SB-75 & 53 & 18.2 & 2.60 & 0.29 & 10 & 15.6 & 2.40 & 0.44 & 37 & 0.72 & & & $0.37[0.37]$ \\
\hline SB-60 & 44 & 18.3 & 2.60 & 0.29 & 11 & 16.0 & 2.45 & 0.30 & 44 & 0.48 & & & $0.44[0.47]$ \\
\hline SB-45 & 35 & 18,3 & 2.60 & 0.26 & 13 & 16.0 & 2.45 & 0.41 & 53 & 0.20 & & & $0.53[0.57]$ \\
\hline SB-30 & 28 & 18.3 & 2.60 & 0.34 & 7 & 15.5 & 2.44 & 0.31 & 40 & 0.42 & 26 & -1.14 & $0.66[0.71]$ \\
\hline SB-15 & 14 & 17.9 & 2.47 & 0.38 & 9 & 16.2 & 2.41 & 0.69 & 77 & -0.66 & & & $0.77[0.77]$ \\
\hline NS-20 & 9 & 17.8 & 2.48 & 0.38 & 12 & 15.0 & 2.40 & 0.68 & 78 & -1.31 & & & $0.78[0.78]$ \\
\hline NS-25 & 14 & 17.9 & 2.47 & 0.38 & 9 & 16.2 & 2.41 & 0.69 & 77 & -0.66 & & & $0.77[0.77]$ \\
\hline NS-30 & 21 & 17.9 & 2.47 & 0.38 & 7 & 16.2 & 2.41 & 0.69 & 72 & -0.26 & & & $0.72[0.75]$ \\
\hline NS-35 & 31 & 18.2 & 2.45 & 0.42 & 7 & 17.0 & 2.40 & 0.69 & 61 & 0.28 & & & $0.61[0.63]$ \\
\hline NS-40 & 36 & 18.2 & 2.37 & 0.44 & 10 & 17.0 & 2.37 & 0.67 & 54 & 0.40 & & & $0.54[0.54]$ \\
\hline NS-45 & - & - & - & - & 53 & 18.2 & 2.39 & $0.57^{\mathrm{a}}$ & 47 & 0.60 & & & $0.47[0.46]$ \\
\hline ----------- & |----- & ------ & $-\pi$ & ------ & ----- & ------- & - & ----- & ----- & ------ & 10 & -------- & 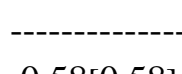 \\
\hline NB40-3S & 16 & 18.7 & 2.57 & 0.42 & 24 & 17.6 & $2.58^{\mathrm{b}}$ & 0.48 & 46 & 0.48 & 12 & -1.26 & $0.58[0.58]$ \\
\hline NS35-3S & 13 & 18,6 & 2.55 & 0.47 & 20 & 17.5 & $2.63^{\mathrm{b}}$ & 0.55 & 53 & 0.11 & 14 & -1.73 & $0.67[0.69]$ \\
\hline NS40-3.5S & 26 & 18.7 & 2.62 & 0.50 & 14 & 17.5 & $2.59^{\mathrm{b}}$ & 0.55 & 31 & 0.43 & 29 & -0.86 & $0.60[0.59]$ \\
\hline NS45-4S & 38 & 18.4 & 2.50 & 0.55 & 10 & 17.3 & $2.56^{\mathrm{b}}$ & 0.56 & 34 & 0.65 & 18 & -0.90 & $0.52[0.53]$ \\
\hline
\end{tabular}

${ }^{a} \mathrm{~B}^{3}$ and $\mathrm{B}^{2}$ units inseparable by simulation; equal parts assumed; ${ }^{\mathrm{b}}$ tentatively assigned to $\mathrm{B}^{2}$ units, albeit uncertain. 
both of these species, the number of bridging oxygen atoms is three, which characterizes them as $\mathrm{B}^{3}$ units in terms of their connectivity.

In glasses with $R>1.5$, the $\mathrm{B}(\mathrm{III})-1$ component is characterized by a distinctly smaller $C_{\mathrm{Q}}$ value $(2.45 \mathrm{MHz})$, and the $\mathrm{B}(\mathrm{III})-2$ unit is characterized by a distinctly larger asymmetry parameter near 0.6 to 0.7 . The latter value signifies $\mathrm{B}(\mathrm{III})$ species in which only two oxygen atoms are bridging, and one is a non-bridging terminal one as, for example, found in alkali metaborates. These species can thus be denoted as $\mathrm{B}^{2}$ units. For such $\mathrm{B}^{2}$ units the local symmetry of the electron distribution around the boron atoms deviates strongly from the trigonal $D_{3 h}$ symmetry, which manifests itself in the larger asymmetry parameter ( 0.6 to 0.7 ) compared to the situation for the $\mathrm{B}^{3}$ units (where $\eta_{\mathrm{Q}}=0$ would be expected for the case of perfect $\mathrm{D}_{3 \mathrm{~h}}$ symmetry). Quantitative estimates for these "asymmetric" three-fold boron units are listed in Tables 2 and 3. Throughout all the glasses with $R>1.5$, their overall contribution to the respective boron inventory appears to be non-negligible, and their contribution increases with increasing $R$ value, consistent with the Raman data (Section 3.2.1). For the glasses with the highest $R$ values, the signal deconvolution in terms of two $\mathrm{B}(\mathrm{III})$ components is ambiguous, and in glass NS-45 ( $R=$ 3), it is possible to simulate the spectrum just by one component, having lineshape parameters intermediate between those of $\mathrm{B}^{2}$ and $\mathrm{B}^{3}$ units. We tentatively interpret this spectrum in terms of about equal contributions; however, it is also conceivable that all of the three-coordinate boron species in this glass are of the $\mathrm{B}^{2}$ type. The trend of increasing $\mathrm{B}^{2}$ unit contributions to the boron speciation with increasing $R$ is also suggested by the Raman scattering data (see section 3.2.1).

The four-coordinated boron species, B(IV), can be simulated in most of the glasses by a simple Gauss-Lorentz curve. In some glasses, the curves are slightly asymmetric, which can be accounted for by a two-component deconvolution. Because of the poor resolution, this analysis 
may appear somewhat arbitrary; we will, therefore, not make specific assignments based on these deconvolution components. Nevertheless, the average chemical shift $\left\langle\delta_{\text {iso }} \mathrm{B}^{4}\right\rangle$ is a parameter whose compositional dependence can be discussed. Here it should be noted that we have assumed all four oxygen atoms to be bridging, i.e., $\mathrm{B}^{4}$ species. Previous ab-initio calculations and experimental results ${ }^{62}$ have shown that $\left\langle\delta_{\text {iso }} \mathrm{B}^{4}\right\rangle$ is sensitive to the linkages to other network formers. Compared to the connectivity with trigonal $\mathrm{B}^{3}$ units, linking to $\mathrm{Si}^{4}$ units produces a shift towards more negative frequencies, whereas linking to anionic $\mathrm{B}^{4}$ units produces a shift towards more positive values. Based on empirical chemical shift trends on sodium borosilicate glasses, as well as the whole body of structural information available in this system, ${ }^{22-29,58,60,63-74}$ we further infer that connectivity to other anionic species such as $\mathrm{B}^{2}$ and $\mathrm{Si}^{3}$ units will also produce chemical shift changes towards more positive values. In general, although a given $\mathrm{B}^{4}$ unit may simultaneously participate in different linkages with varying numbers from one site to the next (e.g., $\mathrm{B}_{4 \mathrm{~B}}^{4}, \mathrm{~B}^{4}{ }_{1 \mathrm{Si} B \mathrm{~B}}, \mathrm{~B}^{4}{ }_{2 \mathrm{Si} 2 \mathrm{~B}}$ etc.), whose chemical shifts are distinct, these units do not lead to resolved peaks in the spectra. Bearing these limitations in mind, the compositional trends of the ${ }^{11} \mathrm{~B}$ NMR parameters within the three distinct compositional series can be summarized as follows:

(1) Within the NB- $x$ series, $R$ increases while $K$ decreases as the $\mathrm{Na}_{2} \mathrm{O} / \mathrm{B}_{2} \mathrm{O}_{3}$ ratio is systematically increased at fixed $\mathrm{SiO}_{2}$ content. Due to these counter-acting effects, $N_{4}$ is found to be only weakly dependent on composition, showing the expected increase with increasing $R$ value below 0.7 , and only a slight decrease at higher $R$ value. This behavior is consistent with the DYB models. ${ }^{22-24}$ At the highest $R$ value $(=2)$ for this series, the spectra show the evidence of $\mathrm{B}^{2}$ units, but their concentration is found to be lower than that predicted in literature. ${ }^{22-24}$ For similar reasons, the $\left\langle\delta_{\mathrm{iso}} \mathrm{B}^{4}>\right.$ parameter is only weakly dependent on alkali content within this series, for 
glasses with $R \leq 1.4$. The positive $\left\langle\delta_{\text {iso }} \mathrm{B}^{4}\right\rangle$ value observed in the glass with the highest $\mathrm{Na}_{2} \mathrm{O}$

content

$(K=R=2)$ 
Table 3. Glass compositions (mole \%), compositional parameters $K=\left[\mathrm{SiO}_{2}\right] /\left[\mathrm{B}_{2} \mathrm{O}_{3}\right]$ and $R=\left[\mathrm{Na}_{2} \mathrm{O}\right] /\left[\mathrm{B}_{2} \mathrm{O}_{3}\right]$, experimental $N_{4}( \pm 0.02)$ and $N_{2}( \pm 0.1)$ values, and corresponding values predicted by the $\mathrm{YDB}_{\text {model }}{ }^{22-24}$, average ${ }^{11} \mathrm{~B}$ isotropic chemical shifts $\left\langle\delta_{\text {iso }}\right\rangle{ }^{11} \mathrm{~B}(\mathrm{IV})$ of the $\mathrm{B}(\mathrm{IV})$ species $( \pm 0.05 \mathrm{ppm})$, for the present sulfur-free baseline glasses and four glasses with $\mathrm{SO}_{3}$ contents $>3$ mol.\%. Additional data* from Stone-Weiss et al. ${ }^{62}$ has been included.

\begin{tabular}{ccccccccccc}
\hline Glass & {$\left[\mathbf{N a}_{\mathbf{2}} \mathbf{O}\right]$} & $\left.\mathbf{[ B}_{\mathbf{2}} \mathbf{O}_{\mathbf{3}}\right]$ & {$\left[\mathbf{S i O}_{\mathbf{2}}\right]$} & $\mathbf{K}$ & $\mathbf{R}$ & $\boldsymbol{N}_{\mathbf{4} \text { exp }}$ & $\boldsymbol{N}_{\mathbf{4} \text { pred. }}$ & $\boldsymbol{N}_{\mathbf{2} \text { exp }}$ & $\boldsymbol{N}_{\mathbf{2} \text { pred }}$ & $\left\langle\boldsymbol{\delta}_{\text {iso }}\right\rangle^{\mathbf{1 1}} \mathbf{B}(\mathbf{I V})$ \\
\hline NB-15 & 15 & 45 & 40 & 0.89 & 0.33 & 0.37 & 0.33 & 0 & 0 & -0.04 \\
NB-25 & 25 & 35 & 40 & 1.14 & 0.71 & 0.61 & 0.55 & 0 & 0.1 & -0.03 \\
NB-30 & 30 & 30 & 40 & 1.33 & 1 & 0.66 & 0.54 & 0 & 0.22 & -0.16 \\
NB-35 & 35 & 25 & 40 & 1.6 & 1.4 & 0.58 & 0.52 & 0 & 0.38 & -0.11 \\
NB-40 & 40 & 20 & 40 & 2 & 2 & 0.51 & 0.51 & 0.21 & 0.47 & 0.42 \\
SB-75 & 25 & 75 & 0 & 0 & 0.33 & 0.37 & 0.33 & 0 & 0 & 0.7 \\
SB-60 & 25 & 60 & 15 & 0.25 & 0.42 & 0.44 & 0.42 & 0 & 0 & 0.5 \\
SB-45 & 25 & 45 & 30 & 0.67 & 0.56 & 0.53 & 0.54 & 0 & 0.01 & 0.2 \\
SB-30 & 25 & 30 & 45 & 1.5 & 0.83 & 0.66 & 0.57 & 0 & 0.12 & -0.19 \\
SB-15 & 25 & 15 & 60 & 4 & 1.67 & 0.77 & 0.7 & 0.09 & 0.23 & -0.66 \\
SB-0 & 25 & 0 & 75 & - & - & - & - & 0 & 0 & - \\
NS-20 & 20 & 15 & 65 & 4.33 & 1.33 & 0.78 & 0.75 & 0.12 & 0.13 & -1.31 \\
NS-25 & 25 & 15 & 60 & 4 & 1.67 & 0.77 & 0.7 & 0.09 & 0.23 & -0.66 \\
NS-30 & 30 & 15 & 55 & 3.67 & 2 & 0.72 & 0.66 & 0.07 & 0.34 & -0.3 \\
NS-35 & 35 & 15 & 50 & 3.33 & 2.33 & 0.61 & 0.61 & 0.07 & 0.37 & 0.3 \\
NS-40 & 40 & 15 & 45 & 3 & 2.67 & 0.54 & 0.56 & 0.2 & 0.4 & 0.4 \\
NS-45 & 45 & 15 & 40 & 2.67 & 3 & 0.47 & 0.51 & $0.25^{\mathrm{a}}$ & 0.43 & 0.6 \\
NB40-3S & 40 & 20 & $40+2.8 \mathrm{SO}_{3}$ & 2 & 2 & 0.58 & 0.51 & $0.24 / 0^{b}$ & 0.47 & 0.12 \\
NS35-3S & 35 & 15 & $50+2.9 \mathrm{SO}_{3}$ & 3.33 & 2.33 & 0.67 & 0.61 & 0.20 & 0.37 & -0.27 \\
NS40-3.5S & 40 & 15 & $45+3.3 \mathrm{SO}_{3}$ & 3 & 2.67 & 0.60 & 0.56 & 0.14 & 0.4 & -0.19 \\
NS45-4S & 45 & 15 & $40+3.9 \mathrm{SO}_{3}$ & 2.67 & 3 & 0.52 & 0.51 & 0.10 & 0.43 & 0.11 \\
PB-0* & 25 & 30 & 45 & 1.5 & 0.83 & 0.63 & 0.57 & 0 & 0.12 & -0.21 \\
MB-0* & 25 & 25 & 50 & 2 & 1 & 0.67 & 0.59 & 0 & 0.16 & -0.65 \\
PA-0* & 25 & 20 & 55 & 2.75 & 1.25 & 0.71 & 0.63 & 0 & 0.19 & -0.38 \\
\hline
\end{tabular}

${ }^{\mathrm{a}} \mathrm{B}^{3}$ and $\mathrm{B}^{2}$ units inseparable by simulation; equal amounts assumed, ${ }^{\mathrm{b}}$ presence of $\mathrm{B}^{2}$ units uncertain; two scenarios considered. 
may be attributed to the connectivity of these $\mathrm{B}^{4}$ species with other anionic species such as $\mathrm{Si}^{3}$ and $\mathrm{B}^{2}$ which are highly concentrated in this glass.

(2) Within the SB-y series, $R$ and $K$ increase simultaneously at fixed $\mathrm{Na}_{2} \mathrm{O}$ content with decreasing $y$. In good quantitative agreement with the DYB predictions, ${ }^{22-24} N_{4}$ strongly increases with increasing $\mathrm{SiO}_{2} / \mathrm{B}_{2} \mathrm{O}_{3}$ ratio. At the highest $R$ value $(R=1.67, K=4)$, the spectra show evidence of $\mathrm{B}^{2}$ units. However, again, their concentration is lower than predicted by DYB. ${ }^{22-24}$ The isotropic chemical shift of the $\mathrm{B}^{4}$ units (calculated as a weighted average in all those cases where two $\mathrm{B}^{4}$ deconvolution components were assumed) decreases monotonically with increasing $K$. In conjunction with the previous ab initio calculations $\left(0.6 \mathrm{ppm}\right.$ for a $\mathrm{B}^{4}{ }_{3 \mathrm{~B}(\mathrm{III}) \mathrm{B}(\mathrm{IV})}$ and $-2.3 \mathrm{ppm}$ for $\mathrm{a} \mathrm{B}_{4 \mathrm{Si}}^{4}$ environment), ${ }^{62}$ we interpret this trend to reflect the successive replacement of $\mathrm{B}-\mathrm{O}-\mathrm{B}$ linkages by $\mathrm{B}-\mathrm{O}-\mathrm{Si}$ linkages as $K$ increases, assuming these connectivities are largely driven by statistical probabilities. In the sample with the highest $K$ value $\left(\mathrm{SB}-15, \mathrm{~K}=4\right.$ ) the most negative $\left\langle\delta_{\mathrm{iso}} \mathrm{B}^{4}>\right.$ value of $-0.66 \mathrm{ppm}$ is measured, in accordance with the highest probability of $\mathrm{B}^{4}-\mathrm{Si}^{4}$ connectivity. The extreme value of $-2.3 \mathrm{ppm}$ for a $\mathrm{B}_{4 \mathrm{Si}}$ is not reached because other linkages, i.e., $\mathrm{B}^{4}-\mathrm{B}^{3}$ and $\mathrm{B}^{4}-\mathrm{Si}^{3}$, still contribute to the experimental shift measured. Our interpretation is in agreement with the previously reported studies on sodium borosilicate glasses. $^{25,26,59,60}$

(3) Within the NS- $z$ series, the effect of increasing alkali ion content in high- $K$ glasses is monitored. Here the main effect is the decrease in $K$ and an increase in $R$ with increasing alkali ion content, which results in a successive replacement of $\mathrm{B}^{4}$ units by $\mathrm{B}^{2}$ units. The observed increase in the $\left\langle\delta_{\mathrm{iso}} \mathrm{B}^{4}>\right.$ parameter with increasing $R$ may again be attributed to the increasing $\mathrm{B}^{4}$ connectivity with anionic $\mathrm{Si}^{3}$ and $\mathrm{B}^{2}$ units, as their concentration increases with increasing $z$. 
Figure 4 and Table 3 illustrate that the $N_{4}$ values for the entire set of glasses agree quite well with the DYB quantitative predictions. ${ }^{22-24}$

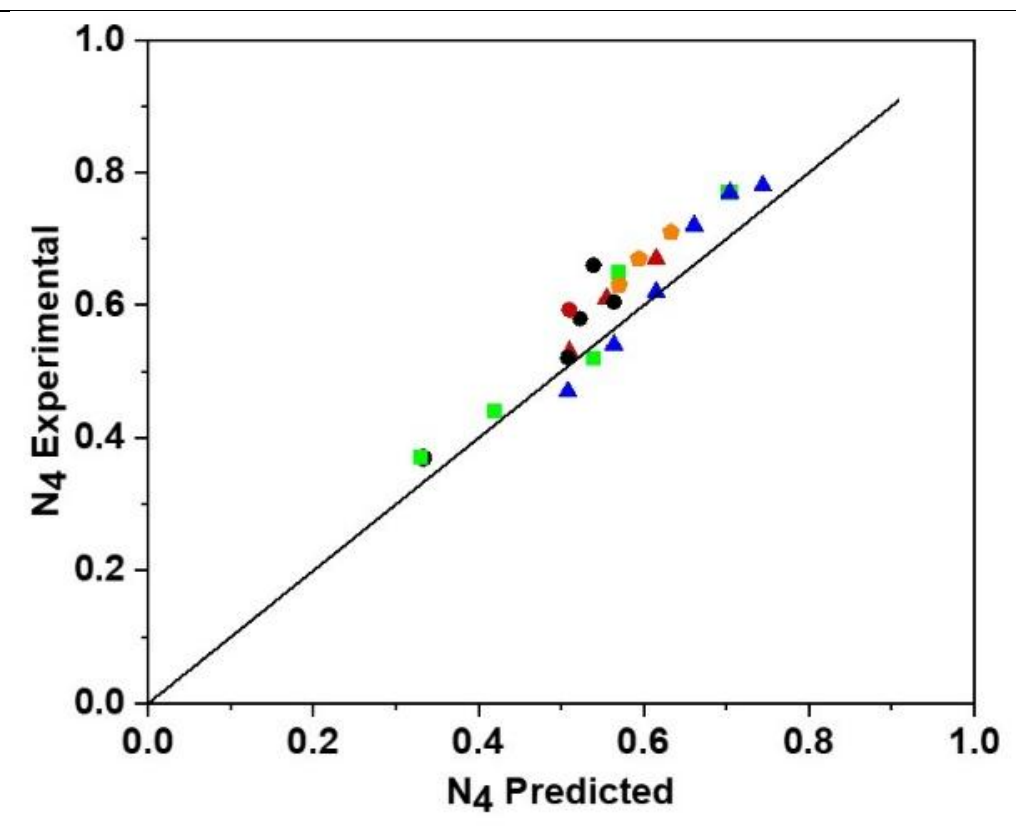

Figure 4. Comparison of the experimental $N_{4}$ values with those predicted using the DYB model. ${ }^{22-24}$ Black circles: NB series, green squares: SB series, blue triangles, NS series, orange diamonds: results from Stone-Weiss et al. ${ }^{62}$. Red symbols denote results from the $\mathrm{SO}_{3}$ containing glasses with $\mathrm{SO}_{3}$ contents $\geq 3$ mol. $\%$.

This is not the case, however, for the concentrations of the $\mathrm{B}^{2}$ units. This discrepancy arises because the DYB model may underestimate the fraction of NBOs created at the silicate units. Nevertheless, the general compositional trends are still reproduced by the data.

\subsection{3. ${ }^{29}$ Si MAS NMR}

Figure 5 summarizes the ${ }^{29} \mathrm{Si}$ MAS NMR data of the sulfur-free baseline glasses. In some cases, such as the borate-free glass SB-0, two well-resolved components at -90.7 and -103.8 ppm are observed, which are easily assigned to $\mathrm{Si}^{3}$ and $\mathrm{Si}^{4}$ units, respectively. For most of the glasses, however, the spectra are poorly resolved, indicating that there is a wide distribution of isotropic chemical shifts that makes it impossible to arrive at an unambiguous deconvolution. 
Nevertheless, regardless of the choice of the deconvolution model, the average chemical shift $<\delta_{\text {iso }}{ }^{29} \mathrm{Si}>$ can be determined without ambiguity. The greatest influence on the ${ }^{29} \mathrm{Si}$ chemical shift arises from the NBO species, such as they are found in $\mathrm{Si}^{3}$ units. It is also well-known that the chemical shift of the $\mathrm{Si}^{4}$ units in silicate glasses increases when these units are connected with $\mathrm{Si}^{3}$ species. ${ }^{75}$ For example, the $\mathrm{Si}^{4}$ species in glass SB-0 is found at $-103.8 \mathrm{ppm}$ instead of -110 ppm in glassy silica. Likewise, $\mathrm{Si}^{4}$ units connected to $\mathrm{B}^{4}$ units in borosilicate are displaced to higher resonance frequencies. ${ }^{62}$ Recent ab initio calculations indicate that the connectivity to the anionic $\mathrm{B}^{4}$ units produces a high-frequency shift by about 5-10 ppm, even though there is no linear dependence of this shift on the number of such linkages. ${ }^{59}$ In this way the parameter $<\delta_{\text {iso }}{ }^{29} \mathrm{Si}>$ reflects the effect of (1) directly bonded NBOs (the $\mathrm{Si}^{3}$ and $\mathrm{Si}^{2}$ units), and (2) the linkage of the $\mathrm{Si}^{n}$ species with other anionic units such as $\mathrm{Si}^{3}, \mathrm{Si}^{2}, \mathrm{~B}^{4}$ and $\mathrm{B}^{2}$. In contrast, the connectivity to the (neutral) $\mathrm{B}^{3}$ species has no effect on $\left\langle\delta_{\mathrm{iso}}{ }^{29} \mathrm{Si}\right\rangle{ }^{60}$

For the glasses in the NB- $x$ and NS- $z$ series, $<\delta_{\text {iso }}{ }^{29} \mathrm{Si}>$ strongly increases with increasing $\mathrm{Na}_{2} \mathrm{O}$ content. This trend mostly reflects the increased contribution of $\mathrm{Si}^{3}$ (and some $\mathrm{Si}^{2}$ in glasses containing $\geq 35 \mathrm{~mol} \% \mathrm{Na}_{2} \mathrm{O}$ ) units to the silicon inventory. In contrast, $<\delta_{\text {iso }}{ }^{29} \mathrm{Si}>$ remains approximately constant in the SB-y glasses. This can be understood as the result of the following two counteracting effects upon the concentration of $\mathrm{Si}^{3}$ units: (1) the decreased $\mathrm{Na}_{2} \mathrm{O} / \mathrm{SiO}_{2}$ ratio associated with the increase in $K$ tends to decrease the fraction of NBOs available for the modification of silicate network; (2) the increase in $K$ also implies that the concentration of the $\mathrm{B}^{4}$ units, which scavenge the network modifier for charge compensation, decreases with increasing $K$ (because of the decreasing boron content), favoring an increase in the relative concentration of the $\mathrm{Si}^{3}$ units. This effect is also confirmed by the Raman scattering results. As a 
result of these two counteracting effects, the ${ }^{29} \mathrm{Si}$ chemical shifts are only weakly dependent on composition within 


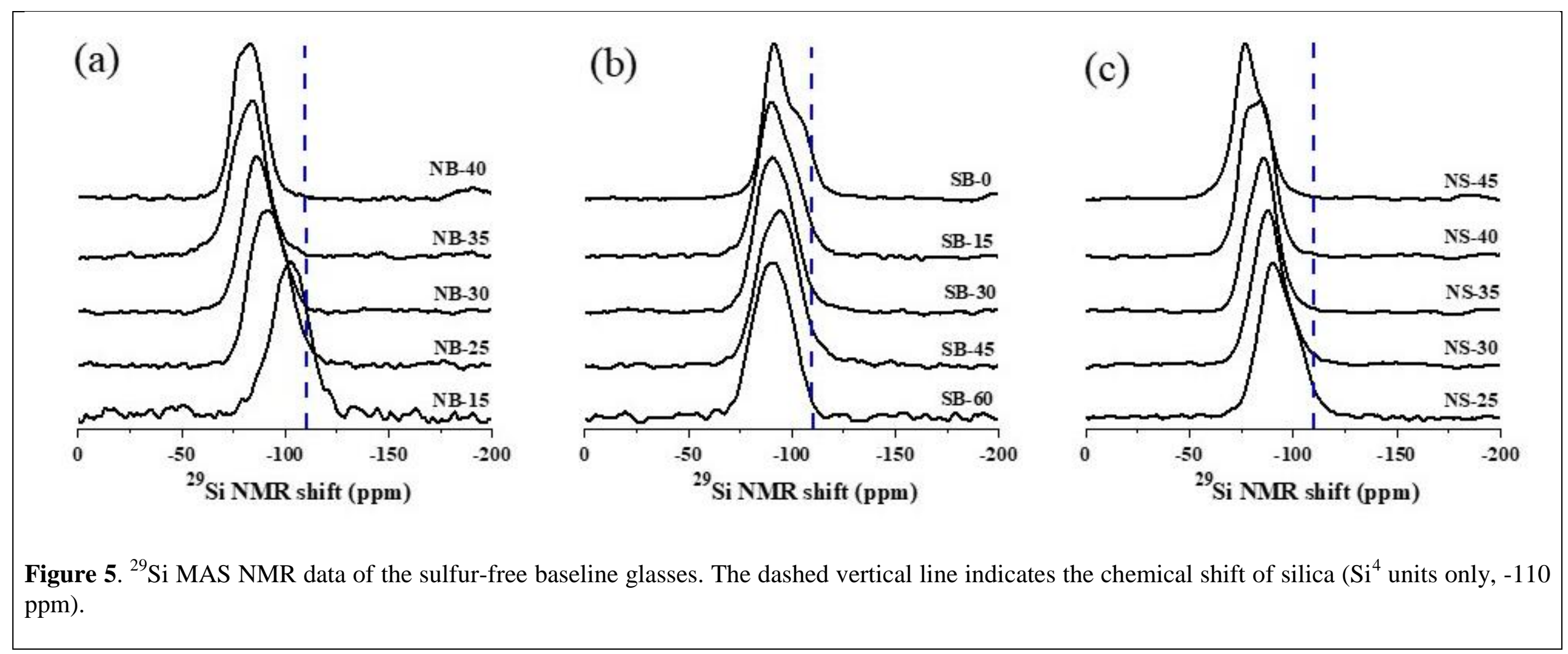


the SB-y series of glasses. Interestingly, the formation of B-O-Si linkages in the SB-y glasses at $R=0.42$ (SB-60 glass) contrasts with the DYB model, ${ }^{22,}{ }^{24}$ which predicts the formation of borosilicate super-structural units (B-O-Si linkages) in sodium borosilicate glasses with $R>0.5$. Further, our results are in agreement with Stebbins and coworkers, ${ }^{26}$ who have demonstrated a considerable degree of Si/B mixing in borosilicate glasses with $R<0.5$ through ${ }^{17} \mathrm{O}$ 3QMAS NMR spectroscopy. Furthermore, the $\mathrm{B}^{3}$ resonance does not show any significant change in lineshape, which indicates that the short-range order around three-coordinated boron remains similar across the compositional range investigated. ${ }^{76}$ A rough estimate of the average number of NBOs per Si unit can be obtained from the "unused balance" of all of the oxide ions introduced by the network modifier $\mathrm{Na}_{2} \mathrm{O}$ that is left over after subtracting the sodium equivalent needed for the creation of anionic $\mathrm{B}^{4}$ or $\mathrm{B}^{2}$ units, as shown in Equation 3 (see Table 4):

$$
<\mathrm{O} / \mathrm{Si}\rangle=\left\{\left[2 \times \mathrm{Na}_{2} \mathrm{O}\right]-2 \times\left[\mathrm{B}_{2} \mathrm{O}_{3}\right] \times\left(\mathrm{N}_{4}+\mathrm{N}_{2}\right)\right\} /\left[\mathrm{SiO}_{2}\right] .
$$

Figure 6 illustrates that this parameter shows a linear correlation with the average ${ }^{29} \mathrm{Si}$ chemical shift measured for the current samples under study, confirming conclusions of the present study. The linear regression of this plot indicates that introduction of one unit of NBOs per silicon produces a change in $\left\langle\delta_{i s o}{ }^{29} \mathrm{Si}\right\rangle$ by $10 \pm 2 \mathrm{ppm}$. This value is close to the chemical shift difference of $13.1 \mathrm{ppm}$ between the $\mathrm{Si}^{4}$ and the $\mathrm{Si}^{3}$ units in the pure sodium silicate glass $\mathrm{SB}-0$. Finally, the large difference (9.2 ppm) in the $\left\langle\delta_{i s o}{ }^{29} \mathrm{Si}>\right.$ values measured for the two glasses with $\mathrm{NBO} / \mathrm{Si}=0$, namely NB-15 and SB-60 arises from their markedly different average numbers of $\mathrm{Si}^{4}-\mathrm{B}^{4}$ linkages: The $\left[\mathrm{B}^{4}\right] /[\mathrm{Si}]$ ratios in $\mathrm{NB}-15$ and $\mathrm{SB}-60$ are 0.8 and 3.5 , respectively. Thus, the probability of a $\mathrm{B}^{4}$ linkage per $\mathrm{Si}$ is much lower in NB-15 than in SB-60 glass, offering a rationale for the large chemical shift difference. 


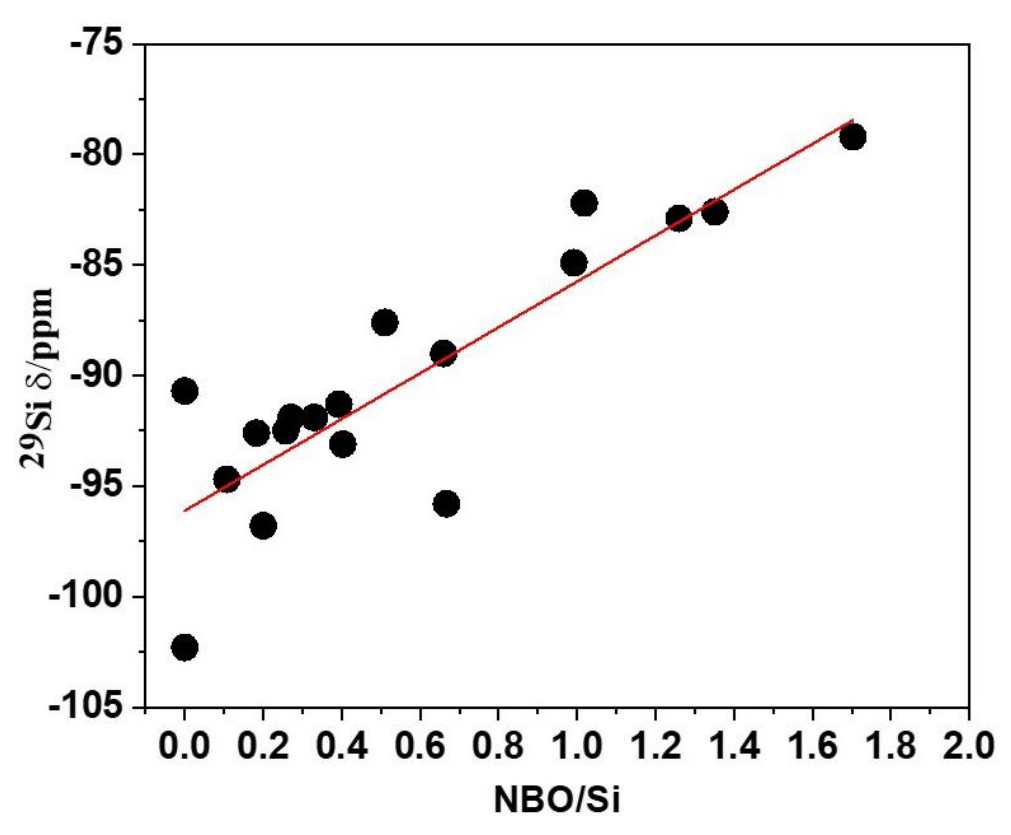

Figure 6. ${ }^{29} \mathrm{Si}$ chemical shift versus average number of non-bridging oxygen atoms, $<\mathrm{NBO} / \mathrm{Si}>$ ratios in the sulfur-free baseline glasses.

Overall, the combined interpretation of the Raman scattering, ${ }^{11} \mathrm{~B}$ and ${ }^{29} \mathrm{Si}$ MAS NMR data suggest the following structural trends:

(1) Increasing $R$ in NB- $x$ glasses at fixed $\mathrm{SiO}_{2}$ content produces a significant depolymerization of the silicate network, and at high $R$ values significant amounts of $\mathrm{B}^{2}$ units are formed.

(2) Increasing $R$ in NS- $z$ glasses at fixed $\mathrm{B}_{2} \mathrm{O}_{3}$ content leads to a similar result. In addition, anionic $\mathrm{B}^{2}$ units are increasingly formed at the expense of $\mathrm{B}^{4}$ units.

(3) Increasing $K$ in SB-y glasses at fixed $\mathrm{Na}_{2} \mathrm{O}$ content promotes the formation of $\mathrm{Si}-\mathrm{O}-\mathrm{B}^{4}$ linkages, while having relatively little impact on the average state of network polymerization. 
Based on the average coordination numbers of the boron and silicon network forming units (NFUs), we can deduce an average network connectivity by quantifying the average fraction of bridging oxygen species per NFU using the Equation 4:

$\langle n\rangle=\left\{2 \times\left[\mathrm{B}_{2} \mathrm{O}_{3}\right] \times\left(4 \times\left[N_{4}\right]+3 \times N_{3}+2 \times N_{2}\right)+\left[\mathrm{SiO}_{2}\right] \times(4-<\mathrm{O} / \mathrm{Si}>)\right\} /\left\{\left[2 \times\left[\mathrm{B}_{2} \mathrm{O}_{3}\right]+\left[\mathrm{SiO}_{2}\right]\right\}(4)\right.$

Table 4. Glass compositions (mole \%), isotropic ${ }^{29} \mathrm{Si}$ chemical shifts $\left\langle\delta_{\text {iso }}{ }^{29} \mathrm{Si}\right\rangle( \pm 0.5 \mathrm{ppm})$, average number of NBOs per Silicon $\langle\mathrm{O} / \mathrm{Si}\rangle$ values $( \pm 0.05)$ deduced from eqn. (4), average NFU coordination number $\langle\mathrm{n}\rangle( \pm 0.02)$, calculated from eqn. (5), glass transition temperatures $T_{\mathrm{g}}$ $\left( \pm 1{ }^{\circ} \mathrm{C}\right)$ and average ${ }^{23} \mathrm{Na}$ chemical shift. $<\delta_{\text {iso }}{ }^{23} \mathrm{Na}>( \pm 0.5 \mathrm{ppm})$ for the present sulfur-free glasses and four glasses with $\mathrm{SO}_{3}$ contents $>3$ mol.\%. Additional data* from Stone-Weiss et al. ${ }^{62}$ has been included.

\begin{tabular}{|c|c|c|c|c|c|c|c|c|}
\hline Glass & {$\left[\mathrm{Na}_{2} \mathrm{O}\right]$} & {$\left[\mathbf{B}_{2} \mathbf{O}_{3}\right]$} & {$\left[\mathrm{SiO}_{2}\right]$} & $\left.<\delta_{\text {iso }}{ }^{29} \mathrm{Si}\right\rangle$ & $<\mathrm{O} / \mathrm{Si}\rangle$ & $<$ n $>$ & $\mathbf{T}_{\mathrm{g}} / \mathrm{K}$ & $\left\langle\delta_{\text {iso }}{ }^{23} \mathrm{Na}\right\rangle$ \\
\hline NB-15 & 15 & 45 & 40 & $-102,3$ & 0 & 3,56 & 499 & -11.8 \\
\hline NB-25 & 25 & 35 & 40 & $-92,6$ & 0,18 & 3.69 & 534 & -8.2 \\
\hline NB-30 & 30 & 30 & 40 & $-87,6$ & 0.51 & 3.59 & 504 & -5.0 \\
\hline NB-35 & 35 & 25 & 40 & $-82,2$ & 1.02 & 3.32 & 473 & -0.5 \\
\hline NB-40 & 40 & 20 & 40 & $-82,9$ & 1.26 & 3.03 & 434 & 1.8 \\
\hline SB-75 & 25 & 75 & 0 & N.D. & 0 & 3.37 & 480 & N.D. \\
\hline SB-60 & 25 & 60 & 15 & $-93,1$ & 0 & 3.50 & 499 & -8.3 \\
\hline SB-45 & 25 & 45 & 30 & $-94,7$ & 0.11 & 3.61 & 524 & -8.0 \\
\hline SB-30 & 25 & 30 & 45 & $-92,5$ & 0.26 & 3.68 & 543 & -8.0 \\
\hline SB-15 & 25 & 15 & 60 & $-93,1$ & 0.40 & 3.62 & 537 & -4.1 \\
\hline SB-0 & 25 & 0 & 75 & $-95,8$ & 0.67 & 3.33 & 496 & -2.2 \\
\hline NS-20 & 20 & 15 & 65 & -96.8 & 0.20 & 3.79 & 573 & -8.1 \\
\hline NS-25 & 25 & 15 & 60 & $-93,1$ & 0.40 & 3.62 & 538 & -4.1 \\
\hline NS-30 & 30 & 15 & 55 & -89 & 0.66 & 3.45 & 496 & -4.2 \\
\hline NS-35 & 35 & 15 & 50 & $-84,9$ & 0.99 & 3.21 & 467 & -1.5 \\
\hline NS-40 & 40 & 15 & 45 & $-82,6$ & 1.28 & 2.97 & 437 & -0.7 \\
\hline NS-45 & 45 & 15 & 40 & -79.2 & 1.70 & 2.69 & 404 & 2.0 \\
\hline NB40-3S & 40 & 20 & $40+2.8 \mathrm{SO}_{3}$ & -82.2 & $1.03 / 1.27^{\mathrm{a}}$ & 3.09 & 438 & -3.5 \\
\hline NS35-3S & 35 & 15 & $50+2.9 \mathrm{SO}_{3}$ & -92.0 & 0.76 & 3.25 & 492 & -4.2 \\
\hline NS40-3.5S & 40 & 15 & $45+3.3 \mathrm{SO}_{3}$ & -85.0 & 1.14 & 3.02 & 448 & -3.0 \\
\hline NS45-4S & 45 & 15 & $40+3.9 \mathrm{SO}_{3}$ & -83.1 & 1.59 & 2.87 & 421 & -0.9 \\
\hline PB-0* & 25 & 30 & 45 & -91.9 & 0.27 & 3.67 & 558 & -4.8 \\
\hline MB-0* & 25 & 25 & 50 & -92.1 & 0.33 & 3.67 & 560 & -3.0 \\
\hline PA-0* & 25 & 20 & 55 & -91.3 & 0.39 & 3.65 & 542 & -5.2 \\
\hline
\end{tabular}

atwo scenarios considered; the second value assuming the absence of $\mathrm{B}^{2}$ units in this glass. ND: not determined. 
The values of $\langle n\rangle$ are listed in Table 4. As shown in Figure 7, they are universally correlated with the values of the glass transition temperature $\left(T_{\mathrm{g}}\right)$ for all the glasses, including a set previously studied in our laboratory. ${ }^{63}$ This correlation also includes the $\mathrm{SO}_{3}$ containing glasses discussed below (red data points in Figure 7), for which the NMR analysis reveals that the NFU average coordination number increases relative to the one found in $\mathrm{SO}_{3}$-free reference glasses (see below).

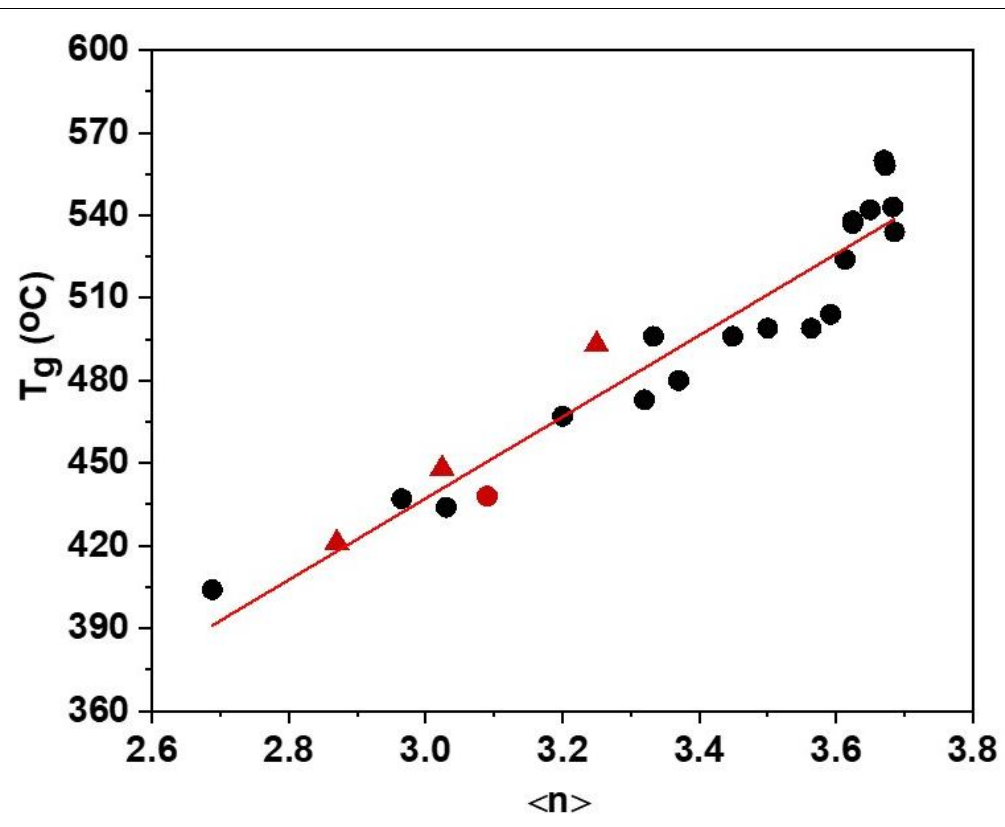

Figure 7. Correlation between $\mathrm{T}_{\mathrm{g}}$ and average connectivity $\langle\mathrm{n}\rangle$ in the sodium borosilicate glasses, as obtained from MAS NMR analysis. Red symbols denote results from the $\mathrm{SO}_{3}$ containing glasses with $\mathrm{SO}_{3}$ contents $\geq 3 \mathrm{~mol} . \%$.

\subsection{4. ${ }^{23} \mathrm{Na}$ MAS NMR}

Figure 8 summarizes the results from ${ }^{23} \mathrm{Na}$ MAS-NMR for the three glass systems under investigation. The spectra display the typical lineshape observed for quadrupolar nuclei requiring analysis in terms of second-order perturbation theory, in the presence of a wide distribution of electric field gradients and magnetic shielding effects. The Czjzek model, as implemented in the DMfit software, was employed to analyze these lineshapes in terms of average isotropic 
chemical shifts, $<\delta_{\text {iso }}{ }^{\text {cs }}{ }^{23} \mathrm{Na}>$ (listed in Table 4) and nuclear electric quadrupolar coupling constants $\left\langle\mathrm{C}_{\mathrm{Q}}\right\rangle$ near 2.0 to $2.4 \mathrm{MHz}$. The following trends can be identified: Within the NB- $x$ and NS- $z$ series, a systematic shift towards higher frequencies is observed, reflecting the increase in $R$ with increasing 

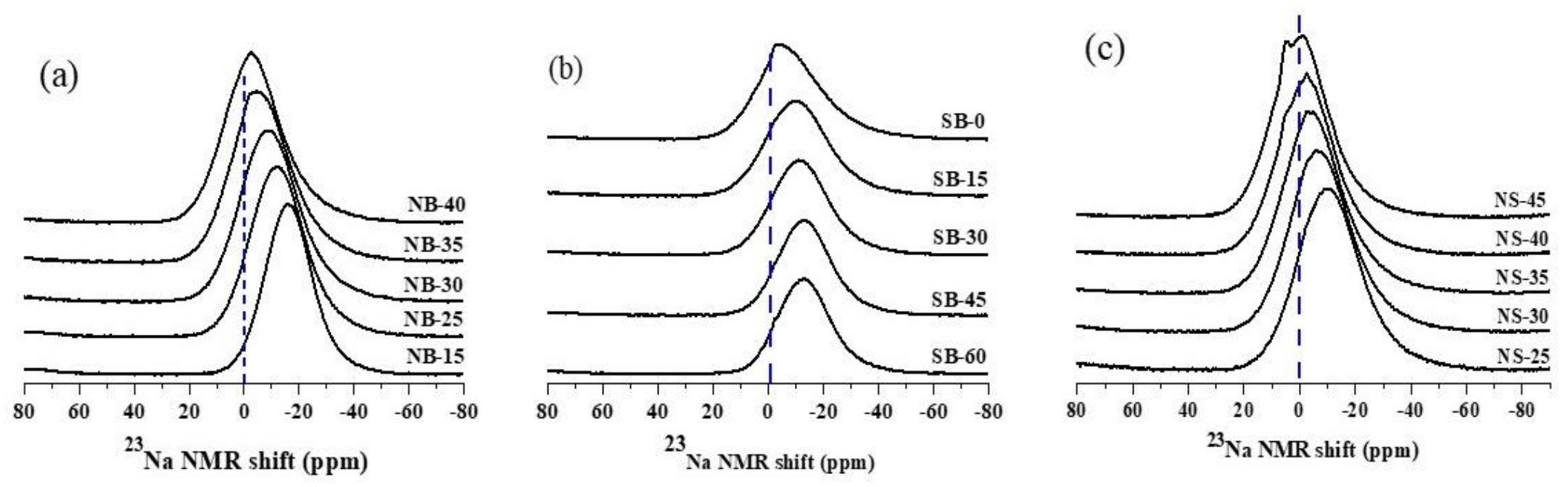

Figure 8. ${ }^{23} \mathrm{Na}$ MAS NMR spectra of the sulfur-free baseline glasses. 
sodium content. This chemical shift change signifies two effects, which are impossible to separate: (1) a systematic change in the distribution of anionic species interacting with the cations, and (2) an overall increase in the number of $\mathrm{Na}^{+\cdots} \mathrm{O} \cdots \mathrm{Na}^{+}$contacts. While in glasses with low $R$ values, the anionic charge compensation proceeds mostly via $\mathrm{B}^{4}$ units, interactions with NBOs associated with $\mathrm{Si}^{3}, \mathrm{Si}^{2}$, and $\mathrm{B}^{2}$ units dominate at higher sodium content. At the same time, the number of shared interactions with $\mathrm{NBO}$ (i.e., $\mathrm{Na}^{+\cdots} \mathrm{O}^{\cdots} \mathrm{Na}^{+}$contacts) keeps increasing.

Within the SB-y series, which is characterized by a systematic change in $\mathrm{B}_{2} \mathrm{O}_{3} / \mathrm{SiO}_{2}$ ratio at fixed $\mathrm{Na}^{+}$content, the change in chemical shift is much less pronounced. For glasses in this compositional series, the charge compensation of the $\mathrm{Na}^{+}$is dominated by the $\mathrm{B}^{4}$ units, at least in glasses with $R<1$. A chemical shift change is only noted in the high- $\mathrm{SiO}_{2}$ glasses (SB-0 and SB15), in which the charge of $\mathrm{Na}^{+}$must be at least partly compensated by NBO species bound to either $\mathrm{Si}^{3}$ or $\mathrm{B}^{2}$ units. As noted before, the interaction with NBOs shifts the resonance line to higher frequency, indicating a stronger bond covalency, and/or stronger $\mathrm{Na}^{+\cdots} \mathrm{O}^{\cdots} \mathrm{Na}^{+}$contacts .

\subsection{Structure of the sulfur-containing glasses}

\subsubsection{Sulfur speciation in glasses}

Sulfur is known to exist in the glasses with valence states ranging from $S^{2-}$ (sulfide) to $S^{6+}$ (sulfate), depending upon the oxidizing/reducing conditions of the glass melt. ${ }^{18-20}$ Polysulfide chains or rings would give rise to $\mathrm{S}-\mathrm{S}$ stretching modes in the region $300-460 \mathrm{~cm}^{-1}$, and for $\mathrm{SO}_{3}{ }^{2-}$ (sulfite) groups two closely spaced bands at $950-970$ and $970-990 \mathrm{~cm}^{-1}$ would be

expected. ${ }^{77-79}$ For the glasses investigated in the present study, we did not find any evidence of sulfur speciation with oxidation state other than +6 , i.e., sulfur is exclusively found in the form of sulfate species. A comparison of Raman spectra of the baseline and sulfur-containing NB- $x$ 
glasses as a representative example to depict the speciation of sulfur in the investigated glasses has
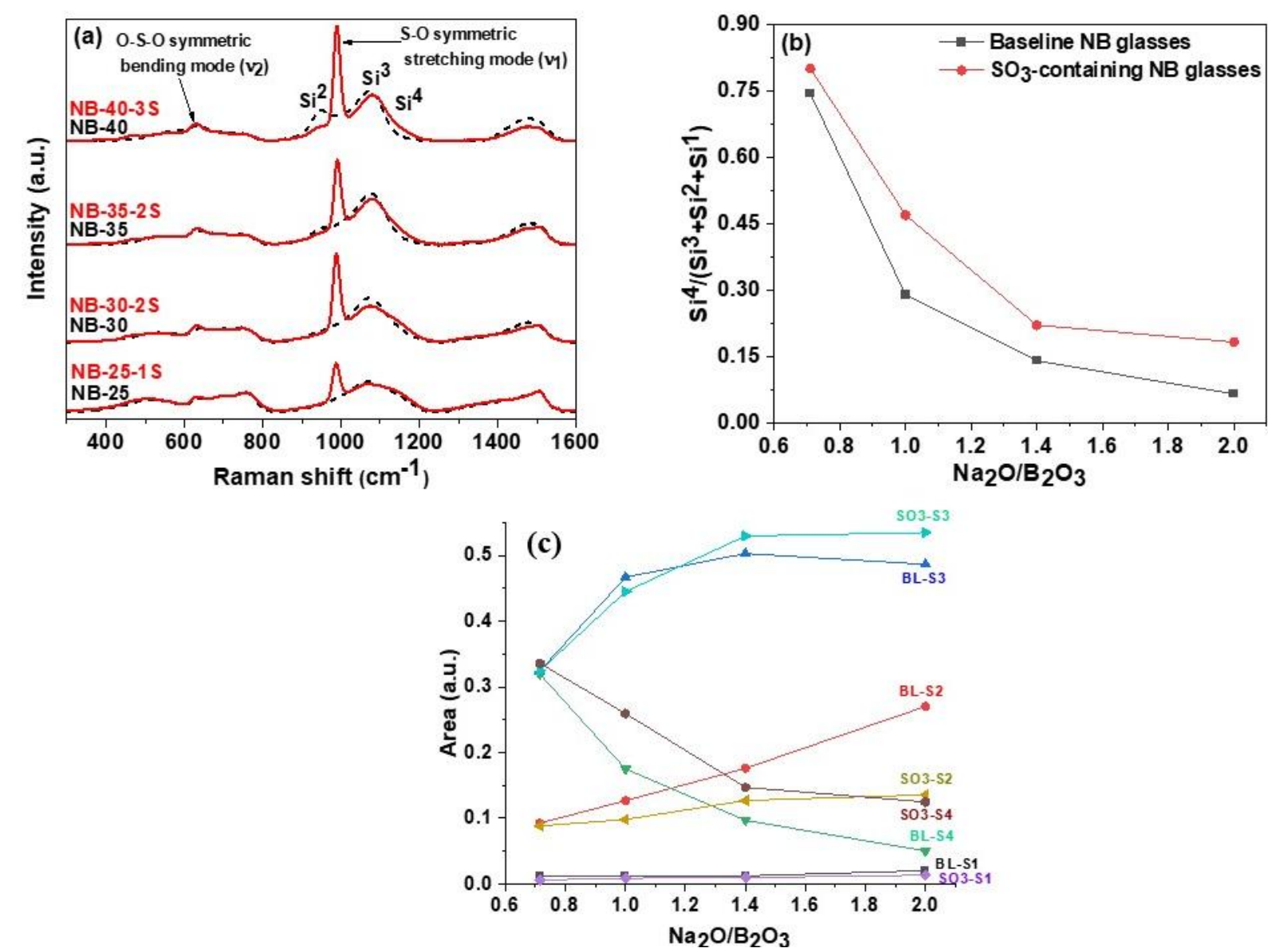

Figure 9. (a) Raman spectra of sulfur-free and corresponding sulfur-containing NB- $x$ glasses as representative example; (b) Comparison of the relative area ratio $\mathrm{Si}^{4} /\left(\mathrm{Si}^{3}+\mathrm{Si}^{2}+\mathrm{Si}^{1}\right)$ for baseline and sulfur-containing NB- $x$ glasses; and (c) Peak area plots of $\mathrm{Si}^{1}, \mathrm{Si}^{2}$ and $\mathrm{Si}^{3}$ units in sulfurfree baseline and sulfur-containing NB- $x$ glasses.

been shown in Figure 9(a). Two new bands can be seen to evolve in the Raman spectra of sulfurcontaining glasses: the band at $469 \mathrm{~cm}^{-1}$ corresponding to asymmetric $\mathrm{S}-\mathrm{O}$ bending modes, and a band at $988 \mathrm{~cm}^{-1}$ attributed to symmetric $\mathrm{O}-\mathrm{S}-\mathrm{O}$ stretching modes. While the group theoretical analysis predicts four vibrational modes assigned as: $v_{1}$ (symmetric S-O stretching modes) $\square 990$ $\mathrm{cm}^{-1} ; v_{2}$ (symmetric $\mathrm{O}-\mathrm{S}-\mathrm{O}$ bending modes) $\square 460 \mathrm{~cm}^{-1} ; v_{3}$ (asymmetric $\mathrm{S}-\mathrm{O}$ stretching modes) $\square 1100 \mathrm{~cm}^{-1}$; and $v_{4}$ (asymmetric O-S-O bending modes) $\square 620 \mathrm{~cm}^{-1,3,15}$ only the bands 
corresponding to the modes characterized by the frequencies $v_{1}$ and $v_{2}$ are visible. The other two modes are difficult to identify because they overlap with bands attributed to vibrational modes associated with the borosilicate network.

In the present work, the sharp band at $988 \mathrm{~cm}^{-1}$ in the glass samples has been taken as the fingerprint of the presence of sulfur as $\mathrm{SO}_{4}{ }^{2-}$ in the investigated glasses, and its intensity increases with increase in $\mathrm{SO}_{3}$ concentration.

\subsubsection{Structural analysis of sulfur-containing glasses by Raman and MAS NMR spectroscopy}

A comparison of the Raman spectra of baseline glasses and sulfur-containing glasses reveals a change in the band positions and intensity of silicate $\left(900-1200 \mathrm{~cm}^{-1}\right)$ and borate stretching regions (1200-1600 $\mathrm{cm}^{-1}$ ), thus reflecting the changes in the concentration and structural configurations of the NFU, as a function of $\mathrm{SO}_{4}{ }^{2-}$ content. In particular, the disappearance of the Raman band near $950 \mathrm{~cm}^{-1}$ attributed to $\mathrm{Si}^{2}$ units and the shift in the position of $\mathrm{Si}^{3}$ band towards higher frequencies is significant; simultaneously a shift in the $500 \mathrm{~cm}^{-1}$ band towards lower frequencies can be noted. Furthermore, Figures 10 (a-c) also indicate significant changes in the ${ }^{11} \mathrm{~B},{ }^{29} \mathrm{Si}$, and ${ }^{23} \mathrm{Na}$ MAS NMR spectra, documenting an increase in $N_{4}$ and a decrease of $\left\langle\delta_{\mathrm{iso}}{ }^{29} \mathrm{Si}\right\rangle$ and $\left\langle\delta_{\text {iso }}{ }^{23} \mathrm{Na}\right\rangle$ in the sulfur-containing glasses relative to the respective baseline glasses. Thus, both the Raman as well as the ${ }^{11} \mathrm{~B}$ and ${ }^{29} \mathrm{Si}$ MAS NMR data clearly indicate a significant increase in network connectivity of the sulfur-containing glasses, involving both the borate and the silicate components. Here, it is noteworthy that the fitting models for the ${ }^{11} \mathrm{~B}$ MAS NMR spectra of the four glasses with the highest $\mathrm{SO}_{3}$ contents, namely NB-40-3S, NS-35-3S, NS-40-3.5S, and NS-45-4S differ significantly from those of the corresponding baseline glasses. For these $\mathrm{SO}_{3}$-containing glasses, a distinct contribution of a high- $\eta_{\mathrm{Q}}$ component is not evident; rather two contributions with different chemical shifts but relatively similar quadrupolar 
coupling parameters are seen. Our assignment of the lower-frequency and higher- $\eta_{\mathrm{Q}}(0.55)$ component to $\mathrm{B}^{2}$ units must be considered tentative: in the case of the NB-40-3S we consider the two possible scenarios of this component reflecting $\mathrm{B}^{2}$ or $\mathrm{B}^{3}$ units.
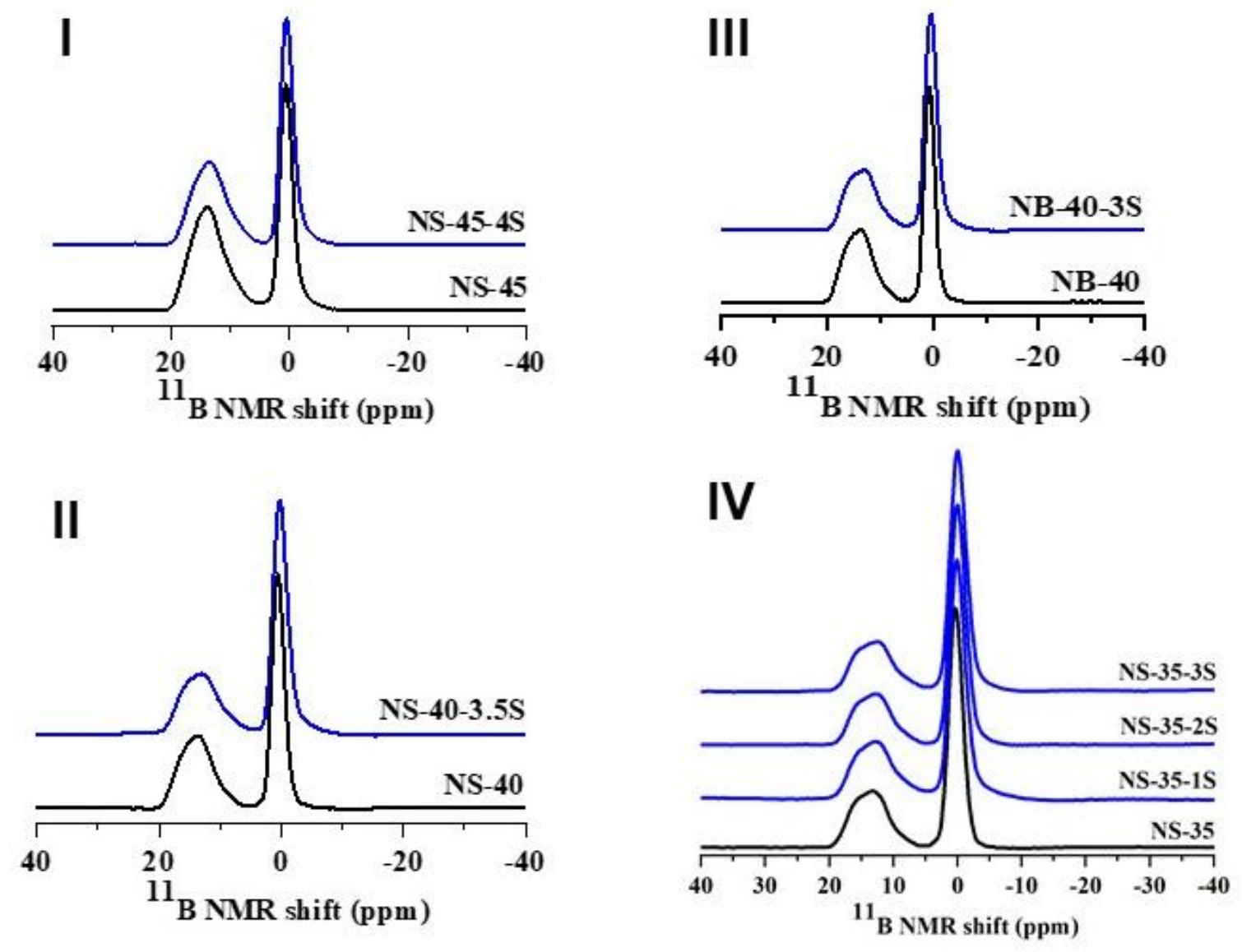

Figure 10a. ${ }^{11} \mathrm{~B}$ MAS NMR spectra of sulfur-free baseline glasses (black color) and $\mathrm{SO}_{3^{-}}$ containing glasses (blue color).

We also tried to quantify the impact of sulfate incorporation on the structure of the investigated glasses from the Raman spectra. To this end, the silicate stretching region (850-1200 $\mathrm{cm}^{-1}$ ) was deconvoluted into seven bands, out of which six bands are the same as those of the baseline glass, as shown in Figures S6-S8, and the seventh band at $988 \mathrm{~cm}^{-1}$ belongs to S-O 
stretching mode in $\mathrm{SO}_{4}{ }^{2-}$ anion. A comparison of $\frac{S i^{4}}{S i^{1}+S i^{2}+S i^{3}}$ and individual $\mathrm{Si}^{n}$ species for sulfur-free and sulfur-containing NB- $x$ glasses is shown in Figures 9(b) and 9(c). The increase in the $\frac{S i^{4}}{S i^{1}+S i^{2}+S i^{3}}$ ratio and individual $\mathrm{Si}^{n}$ species for sulfur-containing glasses as compared to the baseline glasses manifests the increased polymerization of the silicate network upon sulfur incorporation.

Alternatively, we can estimate the $<\mathrm{O} / \mathrm{Si}\rangle$ ratio from the boron speciation in Table 2 (as extracted from the ${ }^{11} \mathrm{~B}$ MAS NMR spectra), if the molar $\mathrm{SO}_{3}$ contents are known. Considering that for each mole of $\mathrm{SO}_{3}$ one equivalent of $\mathrm{Na}_{2} \mathrm{O}$ will not be available for the creation of $\mathrm{NBO}$ species in the silicate network, an expression to this effect can be written as presented in Equation (5), and the resulting values are presented in Table 4.

$$
<\mathrm{O} / \mathrm{Si}>=\left\{2 \times\left[\mathrm{Na}_{2} \mathrm{O}\right]-2 \times\left[\mathrm{SO}_{3}\right]-2 \times\left[\mathrm{B}_{2} \mathrm{O}_{3}\right] \times\left(\mathrm{N}_{4}+\mathrm{N}_{2}\right)\right\} /\left[\mathrm{SiO}_{2}\right]
$$

Indeed, in glasses NS-35-3S, NS-40-3.5S, and NS-45-4S the average number of NBOs per Si, $<\mathrm{O} / \mathrm{Si}\rangle$, is seen to decrease in comparison to the situation in the baseline glasses, which is confirmed by corresponding changes in $\left\langle\delta_{\text {iso }}{ }^{29} \mathrm{Si}\right\rangle$ towards lower values (Table 4). An apparent exception is observed for glass pair NB-40 and NB-40-3S, where there is no apparent change in $<\delta_{\text {iso }}{ }^{29} \mathrm{Si}>$ (see Table 4 and Figure $10 \mathrm{~b}-\mathrm{III}$ ). For this glass, the ${ }^{11} \mathrm{~B}$ MAS NMR spectra show a clear indication of $\mathrm{B}^{2}$ units in the $\mathrm{S}$-free glass, whereas the presence of $\mathrm{B}^{2}$ units in the spectrum of NB-40-3S is less evident, and the two distinct scenarios mentioned above are considered. If in this glass the main effect of $\mathrm{SO}_{3}$ upon the structure is the elimination of $\mathrm{B}^{2}$ units, Table 4 indicates that the degree of polymerization of the silicate network would indeed remain unaffected, thereby providing a rationale for the absence of change in the ${ }^{29}$ Si MAS NMR spectra upon $\mathrm{SO}_{3}$ incorporation (Figure 10b-III). 
A notable influence of sulfur incorporation upon the borate network is indeed also evident from the Raman spectra. The intensity maximum found near $1470 \mathrm{~cm}^{-1}$ shifts towards lower frequencies suggesting a decrease in the concentration of asymmetric $\mathrm{BO}_{2} \varnothing^{-}\left(\mathrm{B}^{2}\right)$ units and an increasing fraction of $\mathrm{B}_{4}\left(\mathrm{~B}^{4}\right)$ units in the glass structure, which corroborates the ${ }^{11} \mathrm{~B}$ MAS NMR analysis of the sulfur-containing glasses (Figure 10a and Tables 2, and 3), revealing an increase in the fraction of $\mathrm{B}^{4}$ units after sulfur incorporation in the glasses.

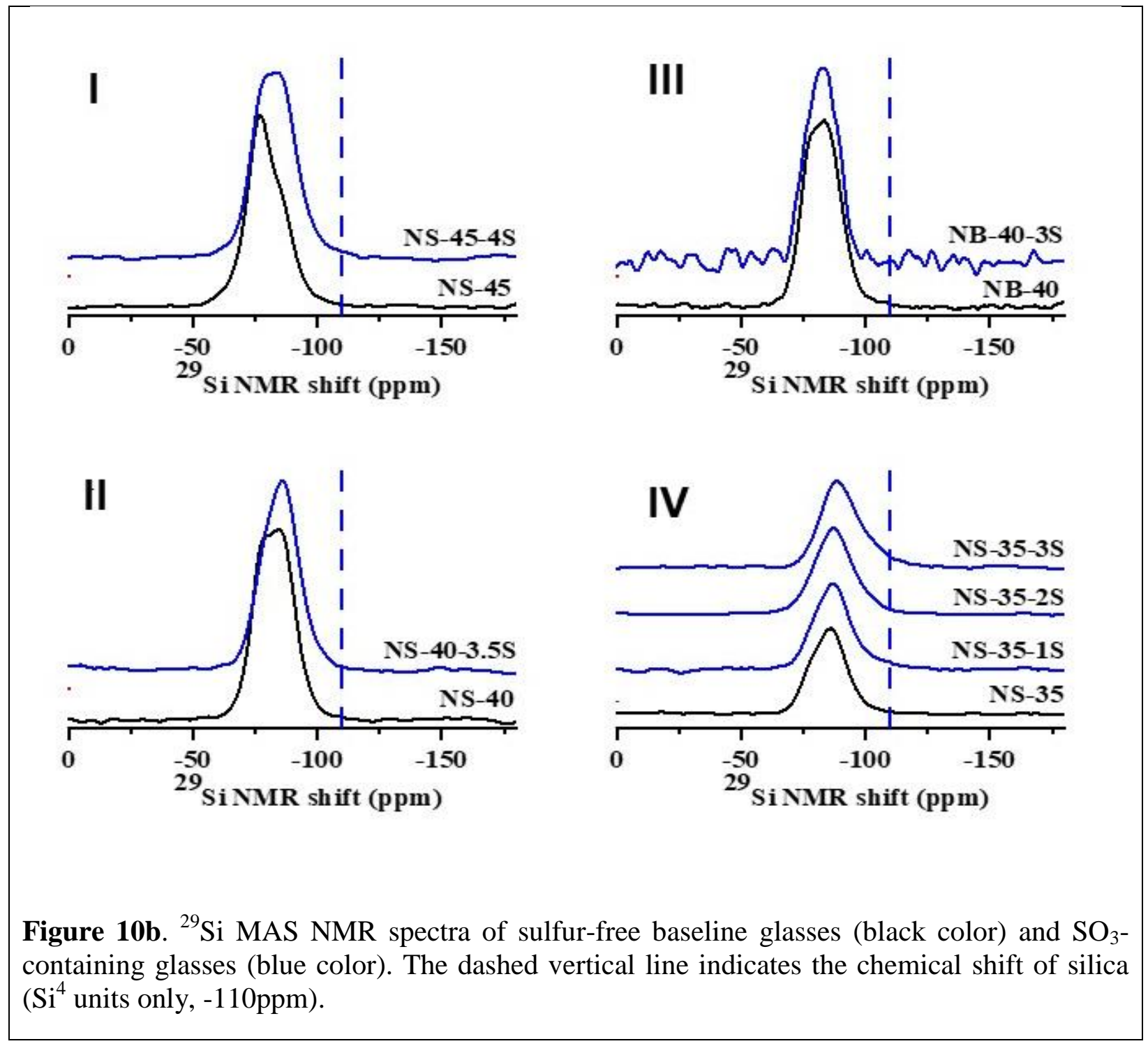


In addition, the ${ }^{23} \mathrm{Na}$ chemical shifts of the $\mathrm{SO}_{3}$-containing glasses are systematically decreased in relation to those of the baseline glasses, reflecting an increased quantitative contribution of the $\mathrm{B}^{4}$ units and the decreased quantitative contribution of NBOs (associated with $\mathrm{B}^{2}, \mathrm{Si}^{3}$ and $\mathrm{Si}^{2}$ units) in the first coordination sphere of the sodium ions. In addition, there is of course the effect of a direct interaction of those (relatively few) sodium ions that find themselves in the first coordination sphere of the sulfate anions, which cannot be separately assessed.

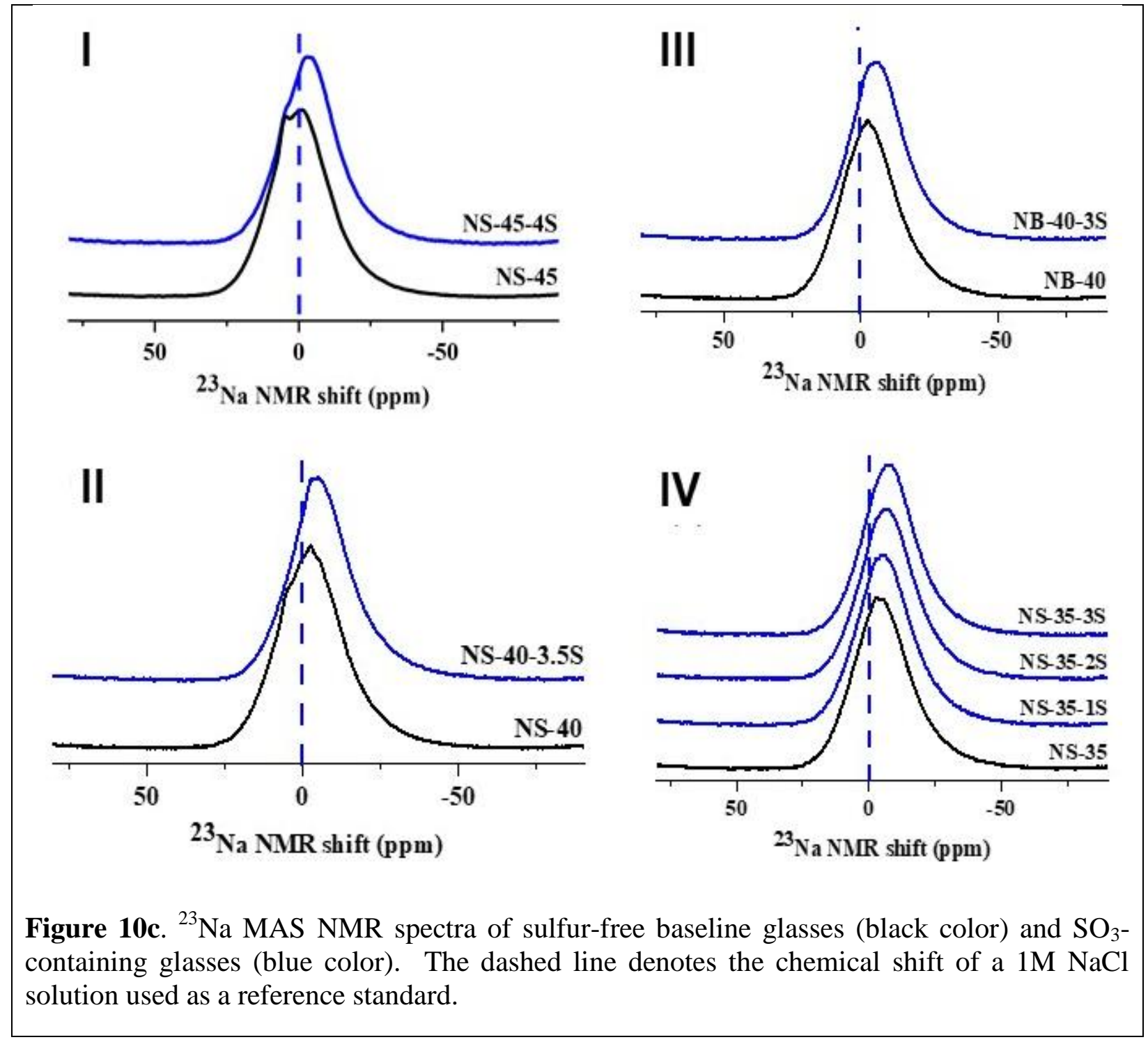


Basically, the incorporated $\mathrm{SO}_{4}{ }^{2-}$ anions can successfully scavenge the NBO-creating $\mathrm{Na}^{+}$ (from the network formers) for their charge compensation. Thus, the $\mathrm{Na}^{+}$attracted by $\mathrm{SO}_{4}{ }^{2-}$ (for charge compensation) is no longer available to break the $\mathrm{B}-\mathrm{O}-\mathrm{B}, \mathrm{Si}-\mathrm{O}-\mathrm{Si}$ or $\mathrm{B}-\mathrm{O}-\mathrm{Si}$ bonds. Consequentially, the formation of NBOs bound to either silicate or trigonal boron species is diminished. In contrast, sulfur incorporation does not affect the modification mechanism leading to the formation of $\mathrm{B}^{4}$ species; the fraction of these units is consistently higher in the $\mathrm{SO}_{3}$ containing glasses than in the baseline glasses. Consequently, the glasses in which the primary modification mechanism is the creation of $\mathrm{B}^{4}$ units have zero or very low $\mathrm{SO}_{3}$ solubility (see Section 4). Finally, consistent with the literature, ${ }^{13,15,18,19,66}$ we did not find any evidence for bridging oxygen species linking sulfate units with the glass network.

\section{Discussion}

\subsection{Sulfur solubility in borosilicate glasses in the context of Dell-Yun-Bray model}

The glass compositions in the present study have been designed in a manner that they can be formally described in terms of the introduction of $\mathrm{SO}_{3}$ into the baseline glass melt, where sulfur

(in the form of $\mathrm{SO}_{4}{ }^{2-}$ ) will compete with silicate and borate units for the fixed amount of $\mathrm{Na}^{+}$. The solubility of $\mathrm{SO}_{3}$ in the melt will thus be controlled by the effectiveness of this competition. As indicated by the results of the present study, the solubility of $\mathrm{SO}_{3}$ in the three glasses in the Region $1(R<0.5)$ of the DYB model, i.e., SB-60, SB-75 and NB-15 (Figure 1), is $\leq 0.5$ mol.\%. According to the NMR and Raman scattering results, these three glasses are close to fully polymerized, i.e., have few NBOs attached to either $\mathrm{B}(\mathrm{III})$ or silicate network. Evidently $\mathrm{SO}_{3}$ competes unsuccessfully with the network forming borate units for the network modifier $\mathrm{Na}^{+}$, thus, allowing the $\mathrm{B}^{3} \rightarrow \mathrm{B}^{4}$ conversion to proceed in an unperturbed manner. As a matter of fact, 
$N_{4}$ systematically increases in the $\mathrm{SO}_{3}$-containing glasses. Because of the higher extent of network connectivity, one also observes that the $\mathrm{SO}_{3}$ containing glasses have significantly increased glass transition temperatures, reflecting the higher average coordination number of the network forming units. The $\mathrm{SO}_{3}$-containing glasses also follow the universal correlation of $T_{\mathrm{g}}$ versus $\langle n\rangle$, supporting the idea that the glasses follow the DYB model if one assumes that an equivalent amount of $\mathrm{Na}_{2} \mathrm{O}$ is removed from the network modification process because it is needed to provide charge compensation for the $\mathrm{SO}_{4}{ }^{2-}$ ions. Finally, although $\mathrm{SO}_{3}$ solubility of glasses in the region $\mathrm{R}<0.5$ is very low, Manara et al. ${ }^{3}$ have reported non-zero $(<0.25$ wt. $\%$ $\mathrm{SO}_{3}$ ) values in such glasses. This may be attributed to a small extent of silicate depolymerization $^{26,80}$ signifying a slight departure from the DYB model. ${ }^{22-24}$ This idea is also supported by the Raman data presented in Figure 2 .

In glass SB-45 representing Region 2 of the DYB model (Figure 1), the $\mathrm{SO}_{3}$ solubility of $0.87 \mathrm{~mol} \%(1.07 \mathrm{wt} . \%)$ is significant (compared to the $\mathrm{SO}_{3}$ solubility in glasses in the Region 1). In addition, the shift of the $490 \mathrm{~cm}^{-1}$ Raman band to $500 \mathrm{~cm}^{-1}$ (Figure 2c), the spectroscopic changes in the $850-1200 \mathrm{~cm}^{-1}$ region and the value of $\left\langle\delta_{1 \mathrm{so}}{ }^{29} \mathrm{Si}>\right.$ (deduced from ${ }^{29} \mathrm{Si}$ MAS NMR spectrum) suggests the formation of NBOs in the silicate network. Furthermore, the appearance of metaborate Raman band near $\square 700 \mathrm{~cm}^{-1}$ suggests the formation of NBOs in the borate network. This interpretation contrasts with the DYB model, ${ }^{22}$ but is consistent with Bunker et al ${ }^{58}$ and Wang et al. ${ }^{59}$ The increased $\mathrm{SO}_{3}$ solubility in the glass SB-45 can thus be correlated with some extent of depolymerization of silicate and borate network in the baseline glass, making some $\mathrm{Na}_{2} \mathrm{O}$ available for charge compensating $\mathrm{SO}_{4}{ }^{2-}$, resulting in an increase in the average coordination number as compared to the baseline glass. The $\mathrm{SO}_{3}$ solubility in glasses in Region 3 
(Figure 1) is higher $(0.90 \mathrm{~mol} . \%(1.12 \mathrm{wt} . \%)$ for NB-25, and $0.96 \mathrm{~mol} \%$ (1.21 wt.\%) for SB-30) than those from Regions

1 and 2. According to DYB model, ${ }^{22-24}$ and confirmed by the present NMR results, in this region the excess $\mathrm{Na}^{+}$(left after the formation of $\mathrm{B}_{4}$ units) creates NBOs in the silicate network, whereas no NBOs are formed in the borate network to a significant extent. The $\mathrm{SO}_{3}$ solubility in glasses in Region 4 (Figure 1) is highest, varying between 1.69 mol. \% (2.1 wt.\%) to 3.86 mol. $\%$ (4.89 wt.\%), owing to the highest degree of depolymerization in the glass network, and availability of excess $\mathrm{Na}^{+}$to charge compensate $\mathrm{SO}_{4}{ }^{2-}$. Region 4 in the present study comprises eight glass compositions, i.e., five from the NS-z series (NS-25, NS-30, NS-35, NS-40, and NS45) and three from the NB- $x$ series (NB-30, NB-35, and NB-40). In both NB- $x$ and the NS- $z$ series, the increased $\mathrm{SO}_{3}$ solubility with increasing sodium content can be correlated to the increased number of NBOs in the silicate and borate networks, as evident from both the NMR and the Raman spectroscopic data. Figure 11 illustrates a good anti-correlation between the $\mathrm{SO}_{3}$ solubility and the average network connectivity $\langle n\rangle$ obtained from the analysis of the NMR data of the baseline glasses.

\subsection{Implications of the present studies in designing advanced borosilicate glass compositions with enhanced $\mathrm{SO}_{3}$ solubility}

As discussed, the sulfur solubility in the investigated glasses is highest in Region 4 of the DYB model (Figure 1), specifically for the glasses in the NS- $z$ series and NB- $x$ series with high $\mathrm{Na}_{2} \mathrm{O}$ concentrations. The glasses in these two series with $\mathrm{SO}_{3}$ solubility $\geq 1.9$ mol \% (2.4 wt.\%) are (from highest to lowest): NS-45>NS-40>NS-35>NB-40>NS-30>NB-35. Of these, the $\mathrm{SO}_{3}$ solubility scales with the $R$ value, i.e., higher the $\mathrm{Na}_{2} \mathrm{O} / \mathrm{B}_{2} \mathrm{O}_{3}$ higher is the $\mathrm{SO}_{3}$ solubility in glasses. 


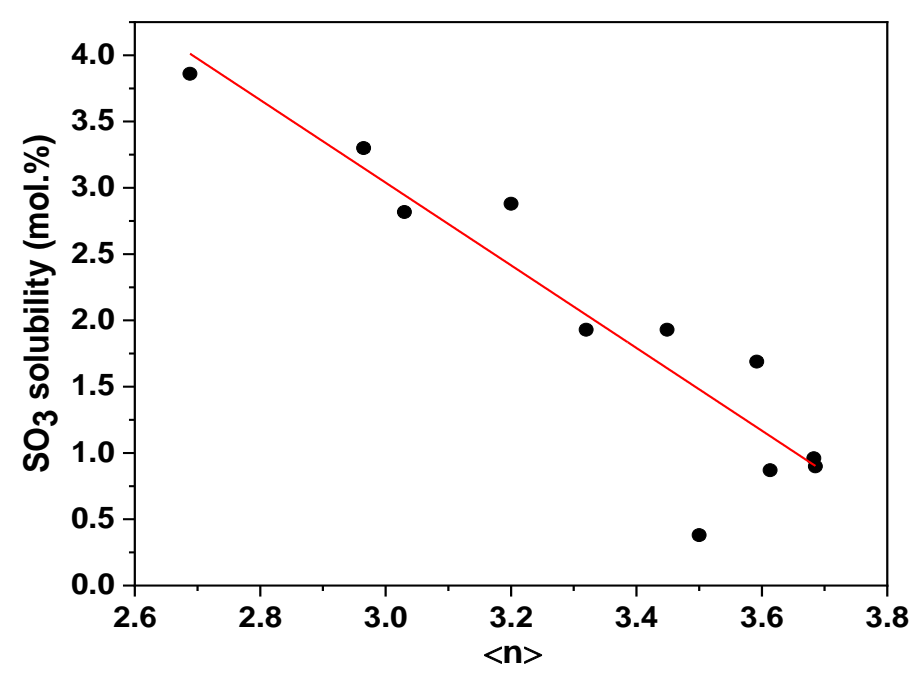

Figure 11. Correlation between $\mathrm{SO}_{3}$ solubility and average connectivity $\langle\mathrm{n}\rangle$ in the sodium borosilicate glasses, as obtained from MAS NMR analysis.
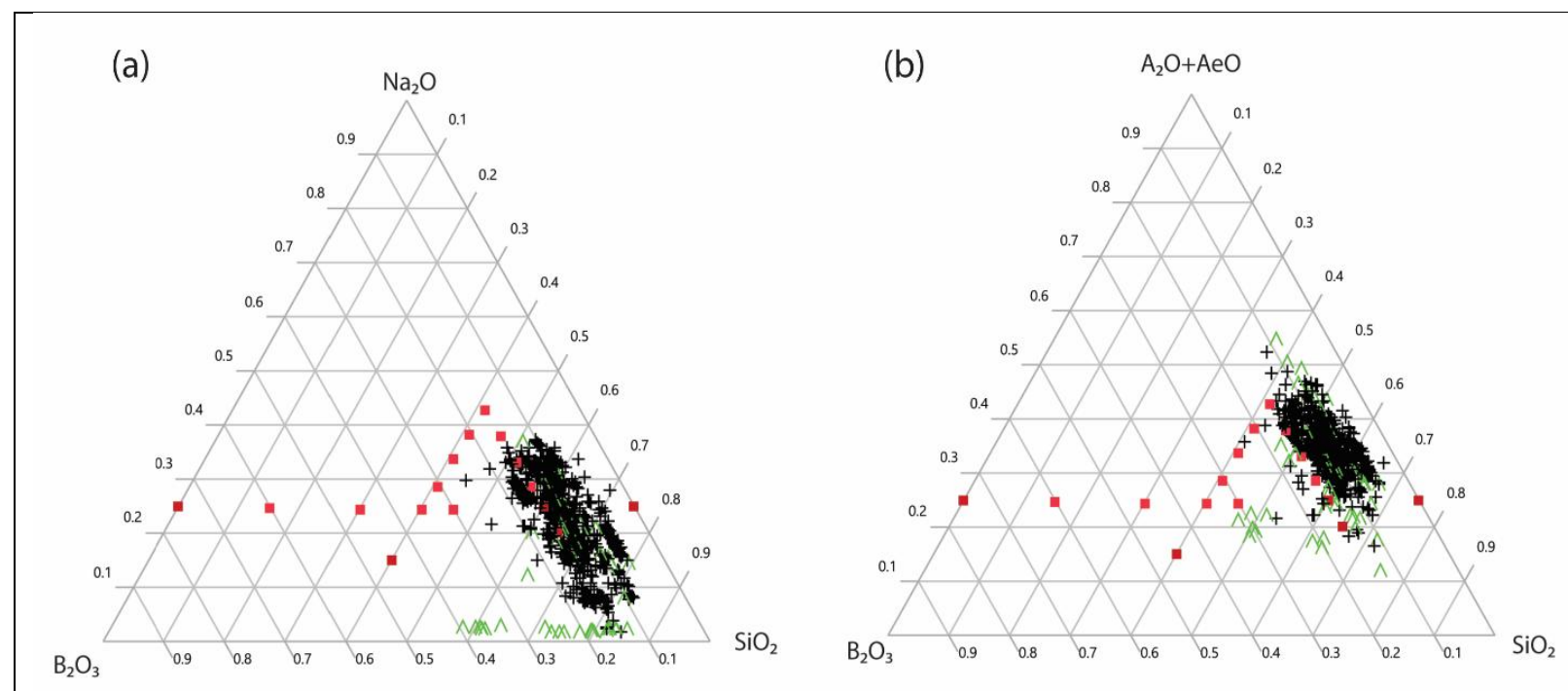

Figure 12. Normalized molar ternary composition diagrams. (a) $\mathrm{SiO}_{2}-\mathrm{B}_{2} \mathrm{O}_{3}-\mathrm{Na}_{2} \mathrm{O}$ and (b) $\mathrm{SiO}_{2}-\mathrm{B}_{2} \mathrm{O}_{3}-\left(\mathrm{A}_{2} \mathrm{O}+\mathrm{AeO}\right)$, where $\mathrm{A}_{2} \mathrm{O}=\mathrm{Li}_{2} \mathrm{O}+\mathrm{Na}_{2} \mathrm{O}+\mathrm{K}_{2} \mathrm{O}+\mathrm{Cs}_{2} \mathrm{O}$ and $\mathrm{AeO}=$ $\mathrm{MgO}+\mathrm{CaO}+\mathrm{SrO}+\mathrm{BaO}$; here LAW glasses are black crosses, HLW glasses are green carats, and glasses from this study are red squares.

Figure $12 \mathrm{a}$, a $\mathrm{Na}_{2} \mathrm{O}-\mathrm{B}_{2} \mathrm{O}_{3}-\mathrm{SiO}_{2}$ molar ternary phase diagram, compares the compositions from the present study to $\sim 950 \mathrm{LAW}^{3,5,7,19,81-92}$ and $\sim 50 \mathrm{HLW}^{2,86,93-96}$ formulations of 
simulated nuclear waste glasses, wherein the complex oxide LAW and HLW glass compositions are normalized to these three components. It is evident that most LAW glasses are to the low $\mathrm{B}_{2} \mathrm{O}_{3}$ side of the ternary spanning across all the regions of the DYB ternary diagram (Figure 1) with majority of them located in the Region 4. Figure 12b shows the same compositions but now normalized to the total alkali $\left(\mathrm{Li}_{2} \mathrm{O}+\mathrm{Na}_{2} \mathrm{O}+\mathrm{K}_{2} \mathrm{O}+\mathrm{Cs}_{2} \mathrm{O}\right)$ and alkaline earth $(\mathrm{MgO}+\mathrm{CaO}+\mathrm{SrO}+\mathrm{BaO})$ content rather than only $\mathrm{Na}_{2} \mathrm{O}$. The comparisons with total alkali only appear similar for LAW glasses, but HLW glasses have considerably more alkaline-earths, so normalized compositions move closer to this corner. Whether considering only $\mathrm{Na}_{2} \mathrm{O}$ or total alkali plus alkaline earth oxides, the normalized LAW compositions are similar to the NS- $z$ series of glasses investigated here, those that showed the highest sulfur solubility and whose structure has been described here.

The significance of this comparison is that it demonstrates that higher $R$ should drive higher sulfur solubility due to the (1) depolymerization of the glass network, (2) availability of $\mathrm{Na}_{2} \mathrm{O}$ for charge compensation of $\mathrm{SO}_{4}{ }^{2-}$, and (3) reduction of the content of $\mathrm{B}_{2} \mathrm{O}_{3}$ which competes with $\mathrm{SO}_{4}{ }^{2-}$ for $\mathrm{Na}^{+}$in converting $\mathrm{B}^{3}$ to $\mathrm{B}^{4}$ units. The insights from the current study support the empirical prediction of positive coefficients for alkali and alkaline earth oxides in the sulfur solubility model (Eq. 1), as depolymerizing agents, ${ }^{4}$ as well as the negative coefficient for $\mathrm{Al}_{2} \mathrm{O}_{3}$ as a polymerizing agent competing for $\mathrm{Na}_{2} \mathrm{O}$ (please refer to Table S2). The large negative values for $\mathrm{Cl}$ and $\mathrm{Cr}_{2} \mathrm{O}_{3}$ probably relate to their propensity for creating the molten salt phase and thus, removing $\mathrm{Na}_{2} \mathrm{O}$ (or other alkali) from the glass to the salt phase, thus reducing the ability to incorporate $\mathrm{SO}_{3}$ in the glass. The reason for positive coefficients for $\mathrm{B}_{2} \mathrm{O}_{3}$ and $\mathrm{SiO}_{2}$ is still unclear. Note, however, that the $\mathrm{SO}_{3}$ solubility model (Eq. 1) does not correctly predict the order 
of glass compositions in terms of their $\mathrm{SO}_{3}$ solubility (from highest to lowest): NB-45>NB40>NS-45 $>$ NS-35>NS-30, as has been shown in Table S3.

Thus, at first look, it may be suspected that enhancement in the $\mathrm{SO}_{3}$ solubility in nuclear waste glasses, particularly LAW glasses, can be made by simply increasing $\mathrm{Na}_{2} \mathrm{O}$ concentration (which would be akin to increasing waste loading since most of the waste is caustic including high concentrations of $\mathrm{Na}^{+}$). However, it is known that an increase in $\mathrm{Na}_{2} \mathrm{O}$ can also have negative effects, particularly on the chemical durability. In the present study, this is evident from the predictions from the vapor hydration test (VHT) and product consistency test (PCT) models for LAW glasses (Tables S4-S7). ${ }^{4}$ According to the VHT model, the glass NS-45 (with the highest measured $\mathrm{SO}_{3}$ solubility) is expected to be exhibit highest rate of corrosion (largest alteration thickness) followed by NB-40 and NS-40, the result being primarily driven by their $\mathrm{Na}_{2} \mathrm{O}$ content. For the LAW PCT model, the worst performance (highest normalized release of $\mathrm{Na}, \mathrm{B}$ ) of the six glasses with highest $\mathrm{SO}_{3}$ solubility has been predicted from NB-35, driven by its low $\mathrm{SiO}_{2}$ content, followed by NS-45, again driven by its high $\mathrm{Na}_{2} \mathrm{O}$ concentration.

Thus, while it is tempting to simply add more $\mathrm{Na}_{2} \mathrm{O}$ to improve sulfur solubility, it can have severe impact on the chemical durability of the final waste form. Therefore, the approach for increasing sulfur in the nuclear waste glasses must then be to increase network depolymerization with other components such as $\mathrm{Li}_{2} \mathrm{O}$ or $\mathrm{K}_{2} \mathrm{O}$ (which show less deleterious effects on PCT compared to $\mathrm{Na}_{2} \mathrm{O}$ ), or even alkaline-earths (which show positive coefficients, presumably protective for $\mathrm{Na}$ and $\mathrm{B}$ release). Any composition changes to improve the waste form performance must also be balanced by constraints for processing, such as viscosity, melting temperature, and electrical conductivity. Thus, the real value of the present study is to provide structural insight into the mechanisms of sulfur incorporation that could not be obtained for 
realistic compositions due to their complexity. These structural insights allow the rationalization of the empirical models used for predicting properties of the complex nuclear waste glasses, thus, leading us towards the development of non-empirical models based on Quantitative Structure Property Relationships.

\section{Conclusions}

The structural dependence of $\mathrm{SO}_{3}$ solubility in sodium borosilicate glasses has been

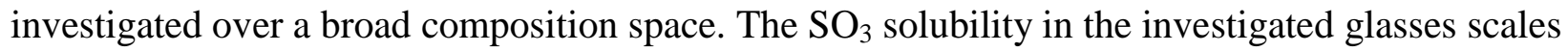
positively with $R$ and can be viewed to be the result of a competition of $\mathrm{SO}_{3}$ with the network formers $\mathrm{B}_{2} \mathrm{O}_{3}$ and $\mathrm{SiO}_{2}$ for the $\mathrm{Na}_{2} \mathrm{O}$ network modifier in the melt. This competition is unsuccessful against the network modification mechanism $\mathrm{B}^{3} \rightarrow \mathrm{B}^{4}$, but effective against the conversion $\mathrm{B}^{3} \rightarrow \mathrm{B}^{2}$ and $\mathrm{Si}^{4} \rightarrow \mathrm{Si}^{3} \rightarrow \mathrm{Si}^{2}$ effected by the modifier. There is no clear evidence that $\mathrm{B}^{2}$ units are present in glasses containing sulfate ions at the level of their maximum solubility. Likely re-polymerization sites include $\mathrm{B}(\mathrm{Si})-\mathrm{O}-\mathrm{Si}^{2}, \mathrm{~B}(\mathrm{Si})-\mathrm{O}-\mathrm{Si}^{3}$ and $\mathrm{B}^{2}-\mathrm{B}^{3}$ linkages. The $\mathrm{SO}_{3}$ solubility shows a negative linear correlation with the average extent of network connectivity $<n>$ derived from NMR studies of the baseline glasses. The low $\mathrm{SO}_{3}$ solubility, 0.38-0.96 mol \% (0.46-1.21 wt.\%), in SB-y series of glasses can be understood in terms of their generally high degree of polymerization. The higher $\mathrm{SO}_{3}$ solubility of NB-x and NS-y series in region 4 arises from the strong tendency towards network depolymerization with increasing alkali content. In particular, the $\mathrm{Si}^{2}$ sites appear to be repolymerized preferentially suggesting that the sulfate ions tend to be localized in regions of a lower degree of polymerization.

\section{Acknowledgements}


This work was supported by funding provided by the Department of Energy (DOE), Office of River Protection, Waste Treatment \& Immobilization Plant (WTP), through contract numbers 89304018CEM000006 and 89304017CEM000001. The support of the Centers for Global Advancement and International Affairs (GAIA) at Rutgers University is acknowledged. The NMR studies were supported by the Center of Research, Technology, and Education on Vitreous Materials, supported by FAPESP project 2013/07793-6. Technical assistance by Dr. Nicholas Stone-Weiss and Dr. Henrik Bradtmüller is gratefully acknowledged.

\section{Supporting Information Description}

Figure S1: X-ray diffractograms of the glass powders for (a) NB-x series, (b) SB-y series, (c) NS-Z series, (d) sulfur-containing glasses, and (e) $\mathrm{Na}_{2} \mathrm{SO}_{4}$ crystalline phase observed as white salt layer over the surface of phase separated NB-40 glass containing 4 mol\% $\mathrm{SO}_{3}$.

Figure S2: Images of the baseline and sulfur-containing NB-x glass samples depicting the solubility limit and white salt layer formation.

Figure S3: Images of the baseline and sulfur-containing SB-y glass samples depicting the solubility limit and white salt layer formation.

Figure S4: Images of the baseline and sulfur-containing $\mathrm{NS}-\mathrm{z}$ glass samples depicting the solubility limit and white salt layer formation.

Figure S5: Linear increase in $\mathrm{SO}_{3}$ solubility for (a) $\mathrm{NB}-\mathrm{x}$ series of glasses with $\mathrm{Na}_{2} \mathrm{O} / \mathrm{B}_{2} \mathrm{O}_{3}$ and (b) NS-z series of glasses with $\mathrm{Na}_{2} \mathrm{O} / \mathrm{SiO}_{2}$ ratio.

Figure S6: Spectral deconvolution of Raman spectra of baseline NB-x series of glasses.

Figure S7: Spectral deconvolution of Raman spectra of baseline SB-y series of glasses. 
Figure S8: Spectral deconvolution of Raman spectra of baseline NS-z series of glasses.

Figure S9: Representative ${ }^{11}$ B MAS-NMR spectra of NB-35 glass at three different magnetic fields and their deconvolutions into one $\mathrm{B}(\mathrm{III})$ and one $\mathrm{B}(\mathrm{IV})$ spectral components. The parameters for the simulation of the $\mathrm{B}(\mathrm{III})$ component are: $\delta_{\text {iso }}=18.9 \mathrm{ppm}, \mathrm{C}_{\mathrm{Q}}=2.68 \mathrm{MHz}, \eta_{\mathrm{Q}}=$ 0.51. Note that the fit leading to perfect agreement with the experimental lineshape at $16.4 \mathrm{~T}$ leads to deviations from the experimental lineshapes at lower fields (compare dashed red and black curves). Experimental conditions at 16.4 T: Agilent DD2 spectrometer, resonance frequency of $224.516 \mathrm{MHz}, 3.2 \mathrm{~mm}$ MAS NMR probe, spinning frequency $20.0 \mathrm{kHz}$ sample spinning, $\pi / 12$ pulses of $0.6 \mathrm{~ms}$, recycle delay $10 \mathrm{~s}$. Experimental conditions at $5.64 \mathrm{~T}$ : Agilent DD2 spectrometer, resonance frequency of $77.20 \mathrm{MHz}, 3.2 \mathrm{~mm}$ MAS NMR probe, spinning frequency $18.0 \mathrm{kHz}$ sample spinning, $\pi / 8$ pulses of $1.0 \mu \mathrm{s}$, recycle delay $3 \mathrm{~s}$.

Figure S10: Representative ${ }^{11}$ B MAS-NMR spectra of NB-35 glass at three different magnetic fields and their deconvolutions into two B(III) and one or two B(IV) spectral components. The parameters for the simulation of the two $\mathrm{B}(\mathrm{III})$ component are: $\delta_{\text {iso }}=18.5$ and $16.1 \mathrm{ppm}, \mathrm{C}_{\mathrm{Q}}=$ 2.57 and $2.58 \mathrm{MHz}, \eta_{\mathrm{Q}}=0.32$ and $0.24 ; 29$ and $13 \%$. Note that the fit leading to perfect agreement with the experimental lineshape at $16.4 \mathrm{~T}$ also leads to good agreement with the experimental lineshapes at lower fields (compare dashed red and black curves). Experimental conditions at 16.4 T: Agilent DD2 spectrometer, resonance frequency of $224.516 \mathrm{MHz}, 3.2 \mathrm{~mm}$ MAS NMR probe, spinning frequency $20.0 \mathrm{kHz}$ sample spinning, $\pi / 12$ pulses of $0.6 \mathrm{~ms}$, recycle delay 10 s. Experimental conditions at 5.64 T: Agilent DD2 spectrometer, resonance frequency of 77.20 MHz, 3.2 mm MAS NMR probe, spinning frequency $18.0 \mathrm{kHz}$ sample spinning, $\pi / 8$ pulses of $1.0 \mu \mathrm{s}$, recycle delay $3 \mathrm{~s}$. 
Figure S11. ${ }^{11}$ B MAS-NMR spectra of baseline NB- $x$ series of glasses and their deconvolutions into two $\mathrm{B}(\mathrm{III})$ and one or two $\mathrm{B}(\mathrm{IV})$ spectral components (red curves). Red dashed curves are the superimposed simulated lineshapes in best agreement with the experimental data (black curves).

Figure S12. ${ }^{11}$ B MAS-NMR spectra of baseline SB-y series of glasses and their deconvolutions into two $\mathrm{B}(\mathrm{III})$ and one or two $\mathrm{B}(\mathrm{IV})$ spectral components (red curves). Red dashed curves are the superimposed simulated lineshapes in best agreement with the experimental data (black curves).

Figure S13. ${ }^{11}$ B MAS-NMR spectra of baseline NS- $z$. series of glasses and their deconvolutions into two B(III) and one or two B(IV) spectral components (red curves). Red dashed curves are the superimposed simulated lineshapes in best agreement with the experimental data (black curves).

Figure S14. ${ }^{11}$ B MAS-NMR spectra and their deconvolutions into two B(III) and one or two $\mathrm{B}$ (IV) spectral components (red curves) for sulfur-containing glasses with $\mathrm{SO}_{3}$ content $\geq 3$ mol.\%. Red dashed curves are the superimposed simulated lineshapes in best agreement with the experimental data (black curves).

Figure S15. Variations of the onset of glass transition temperature $\left(\mathrm{T}_{\mathrm{g}}\right)$ as a function of the relative ratio $\mathrm{Na}_{2} \mathrm{O} / \mathrm{B}_{2} \mathrm{O}_{3}, \mathrm{SiO}_{2} /\left(\mathrm{SiO}_{2}+\mathrm{B}_{2} \mathrm{O}_{3}\right)$ and $\mathrm{Na}_{2} \mathrm{O} / \mathrm{SiO}_{2}$ for (a) $\mathrm{NB}-\mathrm{x}$, (b) $\mathrm{SB}-\mathrm{y}$, and (c) NS$\mathrm{z}$ series of baseline glasses.

Table S1. Batched and ICP-OES analyzed glass composition (shown in brackets within \pm 0.2 wt\%) of NB-x, SB-y, and NS-z series of baseline glasses. 
Table S2. Band assignment, peak position (v), area (A) and FWHM (W) of deconvoluted Raman bands for the baseline glasses.

Table S3. Fitting parameters and N4 values obtained from the ${ }^{11}$ B MAS NMR spectra of NB-35 glass sample at three different magnetic fields and their deconvolutions into one B(III) and one B(IV) spectral components.

Table S4. Fitting parameters and N4 values obtained from the ${ }^{11}$ B MAS NMR spectra of NB-35 glass sample at three different magnetic fields and their deconvolutions into two B(III) and one or two B(IV) spectral components.

Table S5. Coefficients of the recommended $W_{\mathrm{SO}_{3}}$ model for LAW glasses ${ }^{1}$ (in wt.\%) used in the present study.

Table S6. Predicted $\mathrm{SO}_{3}$ solubility values of glasses belonging to region-4 of ternary diagram (Figure 1) using the empirical model for LAW glasses proposed by Vienna et al. ${ }^{1}$ using equation: $W_{S O_{3}}^{\text {Pred }}=\sum_{i=1}^{q} s_{i} n_{i}+\operatorname{selected}\left(\sum_{i=1}^{q} s_{i i} n_{i}^{2}+\sum_{j=1}^{q-1} \sum_{k=j+1}^{q} s_{j k} n_{j} n_{k}\right)$. Here, $W_{S O_{3}}^{\text {Pred }}$ is the predicted $\mathrm{SO}_{3}$ solubility in weight percent, $q$ represents the number of components in the composition with $s$ being the coefficient and $n$ is the normalized mass fraction (wt.\%) of the component as given below in the table.

Table S7. Coefficients of the recommended $\ln ($ VHT $D)$ model for LAW glasses ${ }^{2}$, in $\ln (\mu \mathrm{m})$, used in the present study.

Table S8. Calculated VHT alteration thickness in $\ln (\mathrm{D}, \mu \mathrm{m})$ of the glasses belonging to region-4 of ternary diagram (Figure 1) using the $\operatorname{VHT} \operatorname{model}^{2}$ using the equation: $\ln (D, \mu m)=$ $\sum_{i=1}^{q} b_{i} g_{i}+\operatorname{Selected}\left\{\sum_{i=1}^{q} b_{i i} g_{i}^{2}+\sum_{i=1}^{q-1} \sum_{j=i+1}^{q} b_{i j} g_{i} g_{j}\right\}$. Here, $q$ is number of LAW glass 
components in the model, $b_{i}$ is the coefficient of $i^{\text {th }}$ component in LAW glass, $g_{i}$ is the mass fraction of $i^{\text {th }}$ component in LAW glass, $b_{i i}$ is the coefficient of the squared term of the $i^{\text {th }}$ component in LAW glass, and $b_{i j}$ is the coefficient of the cross-product term involving the $i^{\text {th }}$ and $j^{\text {th }}$ components in LAW glass.

Table S9. Coefficients of the recommended $\ln \left(\mathrm{PCT}\right.$ NL) model for LAW glasses ${ }^{2}$, in $\ln (\mathrm{g} / \mathrm{L})$, used in the present study.

Table S10. Calculated normalized PCT response $(N L)$ of the glasses belonging to region-4 of ternary diagram (Figure 1) using the average natural logarithmic of normalized PCT response $[\ln (N L, \mathrm{~g} / \mathrm{L})]$ model $^{2}$ using the equation:

$\ln (N L, g / L)=\sum_{i=1}^{q} b_{i} g_{i}+\operatorname{Selected}\left\{\sum_{i=1}^{q} b_{i i} g_{i}^{2}+\sum_{i=1}^{q-1} \sum_{j=i+1}^{q} b_{i j} g_{i} g_{j}\right\}$

where $q$ is number of LAW glass components in the model, $b_{i}$ is the coefficient of $i^{\text {th }}$ component in LAW glass, $g_{i}$ is the mass fraction of $i^{t h}$ component in LAW glass, $b_{i i}$ is the coefficient of the squared term of the $i^{\text {th }}$ component in LAW glass, and $b_{i j}$ is the coefficient of the cross-product term involving the $i^{\text {th }}$ and $j^{\text {th }}$ components in LAW glass.

\section{References}

1. Vienna, J. D.; Kim, D.-S.; Muller, I. S.; Piepel, G. F.; Kruger, A. A. Toward Understanding the Effect of Low-Activity Waste Glass Composition on Sulfur Solubility. J. Am. Ceram. Soc. 2014, 97, 3135-3142.

2. Bingham, P. A.; Vaishnav, S.; Forder, S. D.; Scrimshire, A.; Jaganathan, B.; Rohini, J.; Marra, J. C.; Fox, K. M.; Pierce, E. M.; Workman, P.; Vienna, J. D. Modelling the Sulfate Capacity of Simulated Radioactive Waste Borosilicate Glasses. J. Alloys Compd. 2017, 695, 656-667.

3. Manara, D.; Grandjean, A.; Pinet, O.; Dussossoy, J. L.; Neuville, D. R. Sulfur Behavior in Silicate Glasses and Melts: Implications for Sulfate Incorporation in Nuclear Waste Glasses as a Function of Alkali Cation and $\mathrm{V}_{2} \mathrm{O}_{5}$ Content. J. Non Cryst. Solids 2007, 353, 12-23. 
4. Vienna, J. D.; Stanfill, B. A.; Piepel, G. F.; Riley, B. J.; Kim, D. S.; Cooley, S. K.; Crum, J. V.; Jin, T.; Lonergan, C. E. 2016 Update of Hanford Glass Property Models and Constraints for Use in Estimating the Glass Mass to Be Produced at Hanford by Implementing Current Enhanced Glass Formulation Efforts; PNNL-25835; Pacific Northwest National Laboratory, Richland, WA, United States, 2016. https://doi.org/10.2172/1772236

5. Skidmore, C. H.; Vienna, J. D.; Jin, T.; Kim, D.; Stanfill, B. A.; Fox, K. M.; Kruger, A. A. Sulfur Solubility in Low Activity Waste Glass and Its Correlation to Melter Tolerance. Int. J. Appl. Glass Sci. 2019, 10, 558-568.

6. Vienna, J. D.; Kim, D. S.; Muller, I. S.; Piepel, G. F.; Kruger, A. A. Toward Understanding the Effect of Low- activity Waste Glass Composition on Sulfur Solubility. J. Am. Ceram. Soc. 2014, 97, 3135-3142.

7. Muller, I. S.; Gilbo, K.; Chaudhuri, M.; Pegg, I. L.; Joseph, I. K-3 Refractory Corrosion and Sulfate Solubility Model Enhancement (Final Report); ORP-63490_Rev._0; U.S. Department of Energy-Office of River Protection; Richland, WA, United States, 2018. https://doi.org/10.2172/1513833

8. Du, L. S.; Stebbins, J. F. Solid-state NMR study of metastable immiscibility in alkali borosilicate glasses. J. Non Cryst. Solids 2003, 315, 239-255.

9. Goel, A.; McCloy, J. S.; Pokorny, R.; Kruger, A. A. Challenges With Vitrification of Hanford High-level Waste (HLW) to Borosilicate Glass - An Overview. J. Non Cryst. Solids: X 2019, 4, 100033.

10. Muller, I. S.; Gan, H.; Gilbo, K.; Pegg, I. L.; Joseph, I. LAW glass property - composition models for K-3 refractory corrosion and sulfate solubility; VSL-R153270-1; U.S. Department of Energy-Office of River Protection; Richland, WA, United States 2015.

11. Vaishnav, S.; Hannon, A. C.; Barney, E. R.; Bingham, P. A. Neutron Diffraction and Raman Studies of the Incorporation of Sulfate in Silicate Glasses. J. Phys. Chem. C 2020, 124, 5409-5424.

12. Bingham, P.; Connelly, A. J.; Hand, R.; Hyatt, N. C.; Northrup, P. Incorporation and Speciation of Sulphur in Glasses for Waste Immobilisation. Glass Technol.: Eur. J. Glass Sci. Technol. A 2009, 50, 135-138.

13. McKeown, D. A.; Muller, I. S.; Gan, H.; Pegg, I. L.; Stolte, W. C. Determination of sulfur environments in borosilicate waste glasses using X-ray absorption near-edge spectroscopy. $J$. Non Cryst. Solids 2004, 333, 74-84.

14. Pegg, I. L.; Gan, H.; Muller, I. S.; McKeown, D.; Matlack, K. Summary of preliminary results on enhanced sulfate incorporation during vitrification of LAW feeds; VSL-00R3630-1; Vitreous State Laboratory, The Catholic University of America: Washington, DC, United States, 2001.

15. McKeown, D. A.; Muller, I. S.; Gan, H.; Pegg, I. L.; Kendziora, C. A. Raman Studies of Sulfur in Borosilicate Waste Glasses: Sulfate Environments. J. Non Cryst. Solids 2001, 288, 191199. 
16. Mishra, R. K.; Sudarsan, K. V.; Sengupta, P.; Vatsa, R. K.; Tyagi, A. K.; Kaushik, C. P.; Das, D.; Raj, K. Role of Sulfate in Structural Modifications of Sodium Barium Borosilicate Glasses Developed for Nuclear Waste Immobilization. J. Am. Ceram. Soc. 2008, 91, 3903-3907. 17. Kaushik, C. P.; Mishra, R. K.; Sengupta, P.; Kumar, A.; Das, D.; Kale, G. B.; Raj, K. Barium Borosilicate Glass - A Potential Matrix for Immobilization of Sulfate Bearing High-level Radioactive Liquid Waste. J. Nucl. Mater. 2006, 358, 129-138.

18. Lenoir, M.; Neuville, D. R.; Malki, M.; Grandjean, A. Volatilization Kinetics of Sulphur From Borosilicate Melts: A Correlation Between Sulphur Diffusion and Melt Viscosity. J. Non Cryst. Solids 2010, 356, 2722-2727.

19. Lenoir, M.; Grandjean, A.; Poissonnet, S.; Neuville, D. R. Quantitation of Sulfate Solubility in Borosilicate Glasses Using Raman Spectroscopy. J. Non Cryst. Solids 2009, 355, 1468-1473.

20. Lenoir, M. Sulphate Solubility and Sulphate Diffusion in Oxide Glasses: Implications for the Containment of Sulphate-bearing Nuclear Wastes. PhD Thesis, Universite Pierre et Marie Curie, Paris, France, 2009.

21. Bray, P. J.; Emerson, J. F.; Lee, D.; Feller, S. A.; Bain, D. L.; Feil, D. A. NMR and NQR Studies of Glass Structure. J. Non Cryst. Solids 1991, 129, 240-248.

22. Dell, W. J.; Bray, P. J.; Xiao, S. Z. ${ }^{11}$ B NMR Studies and Structural Modeling of $\mathrm{Na}_{2} \mathrm{O}-$ $\mathrm{B}_{2} \mathrm{O}_{3}-\mathrm{SiO}_{2}$ Glasses of High Soda Content. J. Non Cryst. Solids 1983, 58, 1-16.

23. Yun, Y. H.; Feller, S. A.; Bray, P. J. Correction and Addendum to Nuclear Magnetic Resonance Studies of the Glasses in the System $\mathrm{Na}_{2} \mathrm{O}-\mathrm{B}_{2} \mathrm{O}_{3}-\mathrm{SiO}_{2}$. J. Non Cryst. Solids 1979, 33, 273-277.

24. Yun, Y. H.; Bray, P. J. Nuclear Magnetic Resonance Studies of the Glasses in the System $\mathrm{Na}_{2} \mathrm{O}-\mathrm{B}_{2} \mathrm{O}_{3}-\mathrm{SiO}_{2}$. J. Non Cryst. Solids 1978, 27, 363-380.

25. Du, L.-S.; Stebbins, J. F. Site Preference and Si/B Mixing in Mixed-alkali Borosilicate Glasses: A High-resolution ${ }^{11} \mathrm{~B}$ and ${ }^{17} \mathrm{O}$ NMR Study. Chem. Mater. 2003, 15, 3913-3921.

26. Du, L.-S.; Stebbins, J. Nature of Silicon-Boron Mixing in Sodium Borosilicate Glasses: A High-Resolution ${ }^{11}$ B and ${ }^{17}$ O NMR Study. J. Phys. Chem. B 2003, 107, 10063-10076.

27. Lee, S. K.; Musgrave, C. B.; Zhao, P.; Stebbins, J. F. Topological Disorder and Reactivity of Borosilicate Glasses: Quantum Chemical Calculations and ${ }^{17} \mathrm{O}$ and ${ }^{11} \mathrm{~B}$ NMR Study. J. Phys. Chem. B 2001, 105, 12583-12595.

28. van Wüllen, L.; Müller-Warmuth, W.; Papageorgiou, D.; Pentinghaus, H. J. Characterization and Structural Developments of Gel-derived Borosilicate Glasses: A Multinuclear MAS-NMR Study. J. Non Cryst. Solids 1994, 171, 53-67.

29. Mackenzie, J. W.; Bhatnagar, A.; Bain, D.; Bhowmik, S.; Parameswar, C.; Budhwani, K.; Feller, S. A.; Royle, M. L.; Martin, S. W. 29Si MAS-NMR Study of the Short-range Order in Alkali Borosilicate Glasses. J. Non Cryst. Solids 1994, 177, 269-276.

30. Tsujimura, T.; Xue, X.; Kanzaki, M.; Walter, M. J. Sulfur Speciation and Network Structural Changes in Sodium Silicate Glasses: Constraints From NMR and Raman Spectroscopy. Geochim. Cosmochim. Acta 2004, 68, 5081-5101. 
31. Massiot, D.; Fayon, F.; Capron, M.; King, I.; Le Calvé, S.; Alonso, B.; Durand, J. O.; Bujoli, B.; Gan, Z.; Hoatson, G. Modelling One- and Two-dimensional Solid-state NMR Spectra. Magn. Reson. Chem. 2002, 40, 70-76.

32. Massiot, D.; Bessada, C.; Coutures, J.; Taulelle, F. A Quantitative Study of ${ }^{27}$ Al MAS NMR in Crystalline YAG. J. Magn. Reson. 1990, 90, 231-242.

33. Losq, C. L.; Neuville, D. R.; Florian, P.; Henderson, G. S.; Massiot, D. The Role of $\mathrm{Al}^{3+}$ on Rheology and Structural Changes in Sodium Silicate and Aluminosilicate Glasses and Melts. Geochim. Cosmochim. Acta 2014, 126, 495-517.

34. Le Losq, C.; Neuville, D. R. Effect of the Na/K Mixing on the Structure and the Rheology of Tectosilicate Silica-rich Melts. Chem. Geol. 2013, 346, 57-71.

35. Nesbitt, H. W.; O'Shaughnessy, C.; Henderson, G. S.; Michael Bancroft, G.; Neuville, D. R. Factors Affecting Lineshapes and Intensities of $\mathrm{Q}^{3}$ and $\mathrm{Q}^{4}$ Raman Bands of Cs Silicate Glasses. Chem. Geol. 2019, 505, 1-11.

36. Bancroft, G. M.; Nesbitt, H. W.; Henderson, G. S.; O'Shaughnessy, C.; Withers, A. C.; Neuville, D. R. Lorentzian Dominated Lineshapes and Linewidths for Raman Symmetric Stretch Peaks $\left(800-1200 \mathrm{~cm}^{-1}\right)$ in $\mathrm{Q}^{\mathrm{n}}(\mathrm{n}=1-3)$ Species of Alkali Silicate Glasses/Melts. J. Non Cryst. Solids 2018, 484, 72-83.

37. Manara, D.; Grandjean, A.; Neuville, D. R. Advances in Understanding the Structure of Borosilicate Glasses: A Raman Spectroscopy Study. Am. Mineral 2009, 94, 777-784.

38. Xu, X.; Youngman, R. E.; Kapoor, S.; Goel, A. Structural drivers controlling sulfur solubility in alkali aluminoborosilicate glasses. J. Am. Ceram. Soc. 2021, 00, 1-20. https://doi. org/10.1111/jace.17778.

39. Matson, D. W.; Sharma, S. K.; Philpotts, J. A. The Structure of High-silica Alkali-silicate Glasses. A Raman Spectroscopic Investigation. J. Non Cryst. Solids 1983, 58, 323-352.

40. Fukumi, K.; Hayakawa, J.; Komiyama, T. Intensity of Raman band in Silicate Glasses. J. Non Cryst. Solids 1990, 119, 297-302.

41. Mysen, B. O; Frantz, J. D. Raman Spectroscopy of Silicate Melts at Magmatic Temperatures: $\mathrm{Na}_{2} \mathrm{O}-\mathrm{SiO}_{2}, \mathrm{~K}_{2} \mathrm{O}-\mathrm{SiO}_{2}$ and $\mathrm{Li}_{2} \mathrm{O}-\mathrm{SiO}_{2}$ Binary Compositions in the Temperature Range $25-1475^{\circ} \mathrm{C}$. Chem. Geol. 1992, 96, 321-332.

42. Mysen, B. O.; Frantz, J. D. Silicate Melts at Magmatic Temperatures: In-situ Structure Determination to $1651{ }^{\circ} \mathrm{C}$ and Effect of Temperature and Bulk Composition on the Mixing Behavior of Structural Units. Contrib. to Mineral. Petrol. 1994, 117, 1-14.

43. Cochain, B.; Neuville, D. R.; Henderson, G. S.; McCammon, C. A.; Pinet, O.; Richet, P. Effects of the Iron Content and Redox State on the Structure of Sodium Borosilicate Glasses: A Raman, Mössbauer and Boron K-Edge XANES Spectroscopy Study. J. Am. Ceram. Soc. 2012, 95, 962-971.

44. Yano, T.; Kunimine, N.; Shibata, S.; Yamane, M. Structural Investigation of Sodium Borate Glasses and Melts by Raman Spectroscopy.: I. Quantitative Evaluation of Structural Units. J. Non Cryst. Solids 2003, 321, 137-146. 
45. Yano, T.; Kunimine, N.; Shibata, S.; Yamane, M. Structural Investigation of Sodium Borate Glasses and Melts by Raman Spectroscopy. II. Conversion Between $\mathrm{BO}_{4}$ and $\mathrm{BO}_{2} \mathrm{O}^{-}$Units at High Temperature. J. Non Cryst. Solids 2003, 321, 147-156.

46. Yano, T.; Kunimine, N.; Shibata, S.; Yamane, M. Structural Investigation of Sodium Borate Glasses and Melts by Raman Spectroscopy. III. Relation Between the Rearrangement of Superstructures and the Properties of Glass. J. Non Cryst. Solids 2003, 321, 157-168.

47. Lenoir, M.; Grandjean, A.; Linard, Y.; Cochain, B.; Neuville, D. R. The Influence of Si,B Substitution and of the Nature of Network-modifying Cations on the Properties and Structure of Borosilicate Glasses and Melts. Chem. Geol. 2008, 256, 316-325.

48. Meera, B. N.; Ramakrishna, J. Raman Spectral Studies of Borate Glasses. J. Non Cryst. Solids 1993, 159, 1-21.

49. Meera, B. N.; Sood, A. K.; Chandrabhas, N.; Ramakrishna, J. Raman Study of Lead Borate Glasses. J. Non Cryst. Solids 1990, 126, 224-230.

50. Akagi, R.; Ohtori, N.; Umesaki, N. Raman Spectra of $\mathrm{K}_{2} \mathrm{O}-\mathrm{B}_{2} \mathrm{O}_{3}$ Glasses and Melts. J. Non Cryst. Solids 2001, 293-295, 471-476.

51. Osipov, A.; Osipova, L.; Eremyashev, V. Structure of Alkali Borosilicate Glasses and Melts According to Raman Spectroscopy Data. Glass Physics and Chemistry 2013, 39, 105-112.

52. Osipov, A. A.; Osipova, L. M. Structure of Glasses and Melts in the $\mathrm{Na}_{2} \mathrm{O}-\mathrm{B}_{2} \mathrm{O}_{3}$ System From High-temperature Raman Spectroscopic Data: I. Influence of Temperature on the Local Structure of Glasses and Melts. Glass Phys. Chem. 2009, 35, 121-131.

53. Neuville, D. R. Viscosity, Structure and Mixing in (Ca, Na) Silicate Melts. Chem. Geol. 2006, 229, 28-41.

54. Cormier, L.; Meneses, D.; Neuville, D.; Echegut, P. In Situ Evolution of the Structure of Alkali Borate Glasses and Melts by Infrared Reflectance and Raman Spectroscopies. Phys. Chem. Glas.: Eur. J. Glass Sci. Technol. B 2006, 47, 430-434.

55. Peuget, S.; Maugeri, E. A.; Charpentier, T.; Mendoza, C.; Moskura, M.; Fares, T.; Bouty, O.; Jégou, C. Comparison of Radiation and Quenching Rate Effects on the Structure of a Sodium Borosilicate Glass. J. Non Cryst. Solids 2013, 378, 201-212.

56. Cormier, L; Majerus, O; Neuville, D.R.; Calas, G. Temperature-induced Structural Modifications Between Alkali Borate Glasses and Melts. J. Am. Ceram. Soc. 2006, 89, 13-19.

57. Grund Bäck, L.; Ali, S.; Karlsson, S.; Möncke, D.; Kamitsos, E. I.; Jonson, B. Mixed Alkali/alkaline Earth-silicate Glasses: Physical Properties and Structure by Vibrational Spectroscopy. Int. J. Appl. Glass Sci. 2019, 10, 349-362.

58. Bunker, B. C.; Tallant, D. R.; Kirkpatrick, R. J.; Turner, G. L. Multinuclear Nuclear Magnetic Resonance and Raman Investigation of Sodium Borosilicate Glass Structures. Phys. Chem. Glas. 1990, 31, 31-40.

59. Wang, S.; Stebbins, J. F. Multiple-Quantum Magic-Angle Spinning ${ }^{17} \mathrm{O}$ NMR Studies of Borate, Borosilicate, and Boroaluminate Glasses. J. Am. Ceram. Soc. 1999, 82, 1519-1528.

60. Martens, R.; Muller-Warmuth, W. Structural Groups and Their Mixing in Borosilicate Glasses of Various Compositions - An NMR Study. J. Non Cryst. Solids 2000, 265, 167-175. 
61. Wu, J.; Stebbins, J. F. Cation Field Strength Effects on Boron Coordination in Binary Borate Glasses. J. Am. Ceram. Soc. 2014, 97, 2794-2801.

62. Stone-Weiss, N.; Bradtmüller, H.; Fortino, M.; Bertani, M.; Youngman, R. E.; Pedone, A.; Eckert, H.; Goel, A. Combined Experimental and Computational Approach toward the Structural Design of Borosilicate-Based Bioactive Glasses. J. Phys. Chem. C 2020, 124, 1765517674.

63. Xiao, S. Z. A Discussion About the Structural Model of "Nuclear Magnetic Resonance Studies of Glasses in the System $\mathrm{Na}_{2} \mathrm{O}-\mathrm{B}_{2} \mathrm{O}_{3}-\mathrm{SiO}_{2}$ ". J. Non Cryst. Solids 1981, 45, 29-38.

64. El-Damrawi, G.; Müller-Warmuth, W.; Doweidar, H.; Gohar, I. Structure and Heat Treatment Effects of Sodium Borosilicate Glasses as Studied by ${ }^{29} \mathrm{Si}$ and ${ }^{11} \mathrm{~B}$ NMR. J. Non Cryst. Solids 1992, 146, 137-144.

65. Moncke, D.; Ehrt, D.; Eckert, H.; Mertens, V. Influence of Melting and Annealing Conditions on the Structure of Borosilicate Glasses. Phys. Chem. Glas. 2003, 44, 113-116.

66. Wang, S.; Stebbins, J. F. On the Structure of Borosilicate Glasses: a Triple-quantum Magicangle Spinning ${ }^{17} \mathrm{O}$ Nuclear Magnetic Resonance Study. J. Non Cryst. Solids 1998, 231, 286290.

67. Yu, Y.; Stevensson, B.; Edén, M. Direct Experimental Evidence for Abundant $\mathrm{BO}_{4}-\mathrm{BO}_{4}$ Motifs in Borosilicate Glasses From Double-Quantum ${ }^{11}$ B NMR Spectroscopy. J. Phys. Chem. Lett. 2018, 9, 6372-6376.

68. Yu, Y.; Stevensson, B.; Edén, M. A Unified ${ }^{23}$ Na NMR Chemical Shift Correlation With Structural Parameters in Multicomponent Silicate-based Glasses. J. Am. Ceram. Soc. 2020, 103, 762-767.

69. Yu, Y.; Stevensson, B.; Edén, M. Structural Role of Sodium in Borosilicate, Phosphosilicate, and Borophosphosilicate Glasses Unveiled by Solid-State NMR and MD Simulations. J. Phys. Chem. C 2019, 123, 25816-25832.

70. Stevensson, B.; Yu, Y.; Edén, M., Structure-composition Trends in Multicomponent Borosilicate-based Glasses Deduced From Molecular Dynamics Simulations With Improved BO and P-O Force Fields. Phys. Chem. Chem. Phys. 2018, 20, 8192-8209.

71. Krishnamurthy, A; Nguyen, T; Fayek, M; Shabaga, B; Kroeker, S. Network Structural and Dissolution Properties of Phosphate-Doped Borosilicate Glasses. J. Phys. Chem. C 2020, 124, 21184-21194.

72. Parkinson, B. G.; Holland, D.; Smith, M. E.; Larson, C.; Doerr, J.; Affatigato, M.; Feller, S. A.; Howes, A. P.; Scales, C. R. Quantitative Measurement of $Q^{3}$ Species in Silicate and Borosilicate Glasses using Raman Spectroscopy. J. Non Cryst. Solids 2008, 354, 1936-1942.

73. Manara, D.; Grandjean, A.; Neuville, D. R. Structure of Borosilicate Glasses and Melts: A Revision of the Yun, Bray and Dell Model. J. Non Cryst. Solids 2009, 355, 2528-2531.

74. Fábián, M.; Sváb, E.; Mészáros, G.; Révay, Z.; Proffen, T.; Veress, E. Network Structure of Multi-component Sodium Borosilicate Glasses by Neutron Diffraction. J. Non Cryst. Solids 2007, 353, 2084-2089. 
75. Eckert, H., Structural characterization of noncrystalline solids and glasses using solid state NMR. Prog. Nucl. Mag. Reson. Sp. 1992, 24, 159-293.

76. Kapoor, S.; Youngman, R. E.; Zakharchuk, K.; Yaremchenko, A.; Smith, N. J.; Goel, A. Structural and Chemical Approach Toward Understanding the Aqueous Corrosion of Sodium Aluminoborate Glasses. J. Phys. Chem. B 2018, 122, 10913-10927.

77. Ward, A. T. Raman Spectroscopy of Sulfur, Sulfur-selenium, and Sulfur-arsenic mixtures. $J$. Phys. Chem. 1968, 72, 4133-4139.

78. Sourisseau, C.; Cavagnat, R.; Fouassier, M. The Vibrational Properties and Valence Force Fields of $\mathrm{FeS}_{2}, \mathrm{RuS}_{2}$ Pyrites and $\mathrm{FeS}_{2}$ Marcasite. J. Phys. Chem. Solids 1991, 52, 537-544.

79. Twu, J.; Chuang, C. J.; Chang, K. I.; Yang, C. H.; Chen, K. H. Raman Spectroscopic Studies on the Sulfation of Cerium Oxide. Appl. Catal. B: Environ. 1997, 12, 309-324.

80. Furukawa, T.; Fox, K. E.; White, W. B. Raman-Spectroscopic Investigation of the Structure of Silicate-Glasses .3. Raman Intensities and Structural Units in Sodium-Silicate Glasses. J. Phys. Chem. 1981, 75, 3226-3237.

81. Jin, T.; Kim, D.; Darnell, L. P.; Weese, B. L.; Canfield, N. L.; Bliss, M.; Schweiger, M. J.; Vienna, J. D.; Kruger, A. A. A Crucible Salt Saturation Method for Determining Sulfur Solubility in Glass Melt. Int. J. Appl. Glass Sci. 2019, 10, 92-102.

82. Aloy, A. S.; Soshnikov, R. A.; Trofimenko, A. V.; Vienna, J. D.; Elliott, M. L.; Holtzscheiter, E.W. Improved Loading of Sulfate-Limited Waste in Glass. In Waste Management 2006: Global Accomplishments in Environmental and Radioactive Waste Management: Education and Opportunity for the Next Generation of Waste Management Professionals, Tucson, Arizona, 26 Feb - 2 March, 2006; Arizona Board of Regents, Arizona, 2006; Vol. 41, pp PNNL-SA-48798.

83. Vienna, J. D.; Hrma, P.; Buchmiller, W. C.; Ricklefs, J. S. Preliminary Investigation of Sulfur Loading in Hanford LAW Glass; PNNL-14649; Pacific Northwest National Laboratory, Richland, WA, United States, 2004. https://doi.org/10.2172/893257

84. Peeler, D. K. An Assessment of the Sulfate Solubility Limit for the FRIT 418 - Sludge Batch 2/3 System;WSRC-TR-2004-00081,TRN: US0401957; US Department of Eneregy, Savannah River Site, South Carolina, United States, 2004. https://doi.org/10.2172/824040

85. Muller, I. S.; Pegg, I. L.; Gan, H.; Buechele, A.; Rielley, E.; Bazemore, G.; Cecil, R.; Hight, K.; Mooers, C.; Lai, S.-T. T.; Kruger, A. A. Final Report. Baseline LAW Glass Formulation Testing, VSL-03R3460-1, Rev. 0; Department of Energy-Office of River Protection, Richland, WA, United States, 2015. https://doi.org/10.2172/1186012

86. Jantzen, C. M.; Smith, M. E.; Peeler, D. K. Dependency of sulfate solubility on melt composition and melt polymerization. In Environmental Issues and Waste Management Technologies in the Ceramic and Nuclear Industries X Proceedings of the $106^{\text {th }}$ Annual Meeting of the American Ceramic Society, Indianapolis, IN, Vienna, J. D.; Herman, C. C.; Marra, S., Eds.; The American Ceramic Society: Indianapolis, IN, 2004; pp 141-152.

87. Kruger, A. A.; Pegg, I. L.; K.S., M.; Joseph, I.; Muller, I. S.; Gong, W. Final Report LAW Envelope C Glass Formulation Testing to Increase Waste Loading; ORP-56323 Rev 0 
VSL-05R5900-1 Rev 0; Department of Energy-Office of River Protection, The Catholic University of America, Richland, Washington, United States, 2013. https://doi.org/10.2172/1109496

88. Kruger, A. A.; Matlack, K. S. Glass Formulation Testing to Increase Sulfate Incorporation Final Report; VSL-04R4960-1 Rev 0, Vitreous State laboratory, The Catholic University of America: Washington, D.C, United States, 2012. https://doi.org/10.2172/1035193

89. Muller, I. S.; Joseph, I.; Pegg, I. L. Comparison of LAW Simulant, Actual Waste, and Melter Glasses (Final Report, Rev. 0); Vitreous State laboratory, The Catholic University of America: Washington, D.C, United States United States, 2005. https://doi.org/10.2172/1515837

90. Kruger, A. A.; Muller, I. S.; Gilbo, K.; Joseph, I.; Pegg, I. L. Final Report - Enhanced LAW Glass Property - Composition Models - Phase 1; VSL-13R2940-1, Rev. 0; Pacific Northwest National Laboratory: Richland, Washington, 2013.

91. Rielley, E.; Muller, I. S.; Pegg, I. L.; Gan, H.; Cecil, R.; Bazemore, G.; Moncrief, T.; Derr, K. D.; Watts, S.; Mooers, C.; Grant, S.; Feng, C.-F.; Lai, S. T.; Boice, C.; D'Angelo, N.; Su, L.; Liu, Y.; Cheron, J.; Kashnikov, E.; Goloski, L.; Singh, J. Final Report: Preparation and Testing of LAW Matrix Glasses; VSL-04R4480-1, Rev. 0; USDOE Office of Environmental Management (EM), Richland, WA, United States, 2004.

92. Kruger, A. A.; Pegg, I. L.; Matlack, K. S.; Joseph, I.; Muller, I. S.; Gong, W. Final Report - Enhanced LAW Glass Formulation Testing; VSL-07R1130-1, Rev. 0; Pacific Northwest National Laboratory: Richland, Washington, United States, 2013.

93. Kruger, A. A.; Pegg, I. L.; Feng, A.; Gan, H.; Kot, W. K. Final Report - Sulfate Solubility in RPP-WTP HLW Glasse; VSL-06R6780-1, Rev. 0; Pacific Northwest National Laboratory: Richland, Washington, United States, 2013.

94. Kruger, A. A.; Pegg, I. L.; Kot, W.; Gan, H.; Matlack, K. S. Enhanced Sulfate Management in HLW Glass Formulations; VSL12R2540-1 REV 0; Pacific Northwest National Laboratory: Richland, Washington, United States, 2012.

95. Billings, A. L.; Fox, K. M. Retention of Sulfate in Savannah River Site High-Level Radioactive Waste Glass. Int. J. Appl. Glass Sci. 2010, 1, 388-400.

96. Brendebach, B.; Denecke, M.; Roth, G.; Weisenburger, S. Sulfur incorporation in high level nuclear waste glass: A S K-edge XAFS investigation. Journal of Physics: Conference Series 2009, 190, 012186. 